\title{
Modifiable risk factors for carotid atherosclerosis: a meta-analysis and systematic review
}

\author{
Xi Ji ${ }^{1,2}$, Xin-Yi Leng ${ }^{3}$, Yi Dong ${ }^{4}$, Ya-Hui Ma ${ }^{1}$, Wei Xu ${ }^{5}$, Xi-Peng Cao ${ }^{6}$, Xiao-He Hou ${ }^{5}$, Qiang Dong ${ }^{4}$, \\ Lan Tan ${ }^{1,5}$, Jin-Tai Yu \\ ${ }^{1}$ Department of Neurology, Qingdao Municipal Hospital, Dalian Medical University, Dalian 116044, China; ${ }^{2}$ Department of Neurology, Xuchang \\ People's Hospital, Xuchang 461000, China; ${ }^{3}$ Department of Medicine and Therapeutics, The Chinese University of Hong Kong, Prince of Wales \\ Hospital, Hong Kong, China; ${ }^{4}$ Department of Neurology and Institute of Neurology, Huashan Hospital, Shanghai Medical College, Fudan \\ University, Shanghai 200040, China; ${ }^{5}$ Department of Neurology, Qingdao Municipal Hospital, Qingdao University, Qingdao 266071, China; \\ ${ }^{6}$ Clinical Research Center, Qingdao Municipal Hospital, Qingdao University, Qingdao 266071, China \\ Contributions: (I) Conception and design: J Yu, XY Leng; (II) Administrative support: JT Yu; (III) Provision of study materials or patients: JT Yu, L \\ Tan; (IV) Collection and assembly of data: X Ji, YH Ma, W Xu; (V) Data analysis and interpretation: X Ji, YH Ma, W Xu; (VI) Manuscript writing: \\ All authors; (VII) Final approval of manuscript: All authors. \\ Correspondence to: Prof. Jin-Tai Yu, MD, PhD, Department of Neurology and Institute of Neurology, Huashan Hospital, Shanghai Medical College, \\ Fudan University, 12th Wulumuqi Zhong Road, Shanghai 200040, China. Email: jintai_yu@fudan.edu.cn; Prof. Lan Tan, MD, PhD. Department of \\ Neurology, Qingdao Municipal Hospital, Qingdao University, Qingdao 266071, China. Email: dr.tanlan@163.com.
}

Background: Carotid atherosclerosis is a major cause of stroke, but the conclusion about risk factors for carotid atherosclerosis is still controversial. The aim of our present meta-analysis and systematic review was to explore the modifiable risk factors for carotid atherosclerosis.

Methods: We searched PubMed from January 1962 to October 2018 to include longitudinal and crosssectional studies. The results were pooled using random effects model. Heterogeneity was measured by $\mathrm{I}^{2}$ statistic and publication bias was assessed by funnel plots.

Results: A total of 14,700 articles were screened, of which 76 with 27 factors were eligible. Our metaanalysis of cross-sectional studies indicated nine factors (hyperlipidemia, hyperhomocysteinemia, hypertension, hyperuricemia, smoking, metabolic syndrome, hypertriglyceridemia, diabetes, and higher low density lipoprotein) were significantly associated with the presence of carotid plaque, among which four (hyperlipidemia, hyperhomocysteinemia, hypertension, and hyperuricemia) could elevate the risk of atherosclerosis by at least 50\%; and one factor (hypertension) was associated with increased carotid intimamedia thickness. In the systematic review, another five factors [negative emotion, socioeconomic strain, alcohol, air pollution, and obstructive sleep apnea syndrome (OSAS)] were also related to the presence of atherosclerosis. The cross-sectional associations with most of the above 14 factors were further confirmed by longitudinal studies. Among them, the managements of 4 factors (hypertension, hyperlipidemia, diabetes and OSAS) were indicated to prevent carotid atherosclerosis by cohort studies.

Conclusions: Effective interventions targeting pre-existing disease, negative emotion, lifestyle and diet may reduce the risk of carotid atherosclerosis. Further good-quality prospective studies are needed to confirm these findings.

Keywords: Carotid atherosclerosis; carotid plaque; carotid intima-media thickness; risk factors; meta-analysis

Submitted Jul 26, 2019. Accepted for publication Oct 17, 2019.

doi: $10.21037 /$ atm.2019.10.115

View this article at: http://dx.doi.org/10.21037/atm.2019.10.115 


\section{Introduction}

Carotid atherosclerosis is a major cause of ischemic stroke, which remains clinically silent for a long time before an outbreak of acute events. As a global public health problem, stroke is the second leading cause for death worldwide (1), which leads to a huge burden on individuals and society because of the high rate of residual disability (2). Therefore, the prevention of the disease in a subclinical phase is important (3). Among the different stages of carotid atherosclerosis, we selected increased carotid intima media thickness (CIMT) and the presence of carotid plaque because these two were the most commonly used parameters (4).

Recently, it was indicated that healthy lifestyles might contribute to a decline in the prevalence of carotid atherosclerosis in the long term $(5,6)$. In addition, a considerable amount of studies suggested that carotid atherosclerosis could be prevented by medications targeting several comorbidities, such as hypertension, diabetes, and dyslipidemia (7). Nonetheless, the conclusions concerning these potentially modifiable risk factors are still in dispute $(8,9)$. As yet no article has been published on the detail of the risk factors for carotid atherosclerosis. Therefore, we performed a meta-analysis and systematic review to explore the modifiable risk factors for carotid atherosclerosis identified in previous reports, which is expected to throw light on the prevention of carotid atherosclerosis.

\section{Methods}

\section{Search strategy}

We adhered to the meta-analysis in the preferred reporting items for systematic reviews and meta-analyses (PRISMA) guidelines (10). We searched PubMed for studies that reported risk factors for carotid atherosclerosis from January 1962 to October 2018. Search terms were "carotid", "risk", and "risk factor" (the detailed retrieval strategy was shown in Supplementary Material). The reference lists of relevant reviews, meta-analyses and systematic reviews were hand-searched for further supplement.

\section{Inclusion and exclusion criteria}

Longitudinal and cross-sectional studies were included if they fulfilled the following criteria simultaneously: (I) the study included community-based population, (II) the exposures considered to be risk or protective factors for carotid atherosclerosis were potentially modifiable, (III) the control group were people without carotid atherosclerosis, and (IV) the outcome of carotid atherosclerosis was measured by increased carotid intima-media thickness (CIMT) or carotid plaque burden which included both non-stenotic and stenotic plaques (4). Increased CIMT was defined as CIMT $\geq 1.0 \mathrm{~mm}$ whether in the distal wall of the common carotid artery or in the bulb where there is no plaque and the presence of carotid plaque was defined as CIMT $>1.5 \mathrm{~mm}$ or focal structures encroaching into the arterial lumen of at least $0.5 \mathrm{~mm}$ or $50 \%$ of the surrounding CIMT value (2). We restricted our search to those published in English. The detailed exclusion criteria were shown in Figure 1. If there was any disagreement between authors, the articles would be discussed until an agreement was reached.

\section{Data extraction and quality assessment}

General characteristics of studies were extracted, including authors, publication year, baseline characteristics (total sample size, recruitment period, mean age and sex distribution), study design (prospective or cross-sectional), follow-up information (mean or maximum follow-up and the number of lost to follow-up), and outcomes (increased CIMT or the presence of carotid plaque). All data were extracted using an electronic spreadsheet. We preferred multivariate-adjusted OR/RR/HR rather than crude results.

Agency for Healthcare Research and Quality (AHRQ) (11) was used to assess the quality of crosssectional observational studies (Table S1). NewcastleOttawa Scale (NOS) was employed to assess the quality of longitudinal studies (Table S2).

\section{Statistical analyses}

Heterogeneity among studies was assessed using the $\mathrm{I}^{2}$ statistic and values $<75 \%, \mathrm{P}>0.05$ were considered as possibly low heterogeneity (12). A random effects model was used to quantitatively synthesize data. When the heterogeneity was high, the source would be explored further $(13,14)$. First, sensitivity analyses were performed to examine whether the pooled effect was influenced by omitting any single study. Second, subgroup analyses were conducted according to the characteristics of studies (e.g., different outcomes). Funnel plot and trim-and-fill method were used to evaluate whether the asymmetry of funnel plot was related to publication bias (15). All statistical analyses were performed with R 3.2.0 software. 


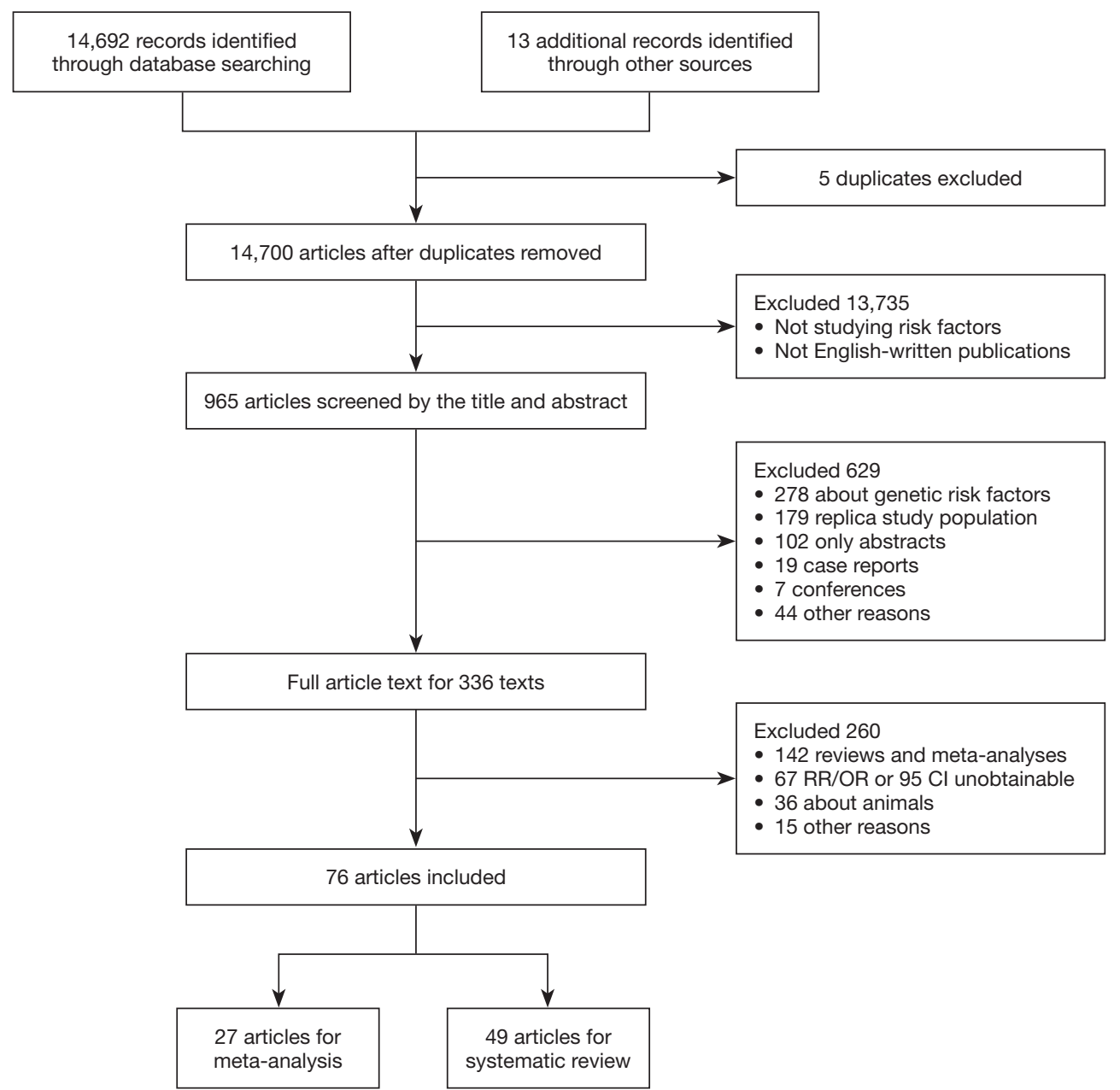

Figure 1 Flow chart of identified studies.

\section{Ethics approval}

It was not required, because the study type of our article is meta-analysis and systematic review.

\section{Results}

A total of 14,700 articles were identified, of which 76 with 27 factors met the inclusion criteria. Finally, eleven factors had data eligible for the meta-analysis and all relevant studies were cross-sectional (Figure 2). The general characteristics of the articles included in the metaanalysis were presented in Table 1. A total of 48,847 subjects were included in the meta-analysis, $92.6 \%$ studies were published from 2005 onwards and $72.8 \%$ samples were recruited from Asia and North America. The age range of all recruited subjects was from 35 to 100 . Where reported, the proportion of females in the samples ranged from $18 \%$ to $67.2 \%$. More baseline characteristics of the included population were presented in Table $S 3$.

Cigarette smokers and people with metabolic syndrome (including its components of hypertension, dyslipidemia, and diabetes mellitus), hyperuricemia, hyperhomocysteinemia, negative emotion, socioeconomic strain, obstructive sleep apnea syndrome (OSAS), alcohol, air pollution, and childhood sexual abuse are more likely to have carotid atherosclerosis. Furthermore, interventions against risk factors may prevent atherosclerosis.

\section{Modifiable risk factors}

\section{Blood pressure}

Data from eight studies (16-23) including 12,474 individuals 


Risk Factors No. of Studie
Hypertension
Plaque $^{\wedge}$
CIMT\#
Hyperhomocysteinemia^
Hyperuricemia^
Smoking^
Current smoking
Former smoking
Metabolic syndrome^
Mets-1
Mets-2
Mets-3
Mets-4
Mets-5
Diabetes mellitus^
Dyslipidemia^
Hyperlipidemia
Hypertriglyceridemia
Higher low density lipoprotein
Hypercholesterolemia
Lower high density lipoprotein

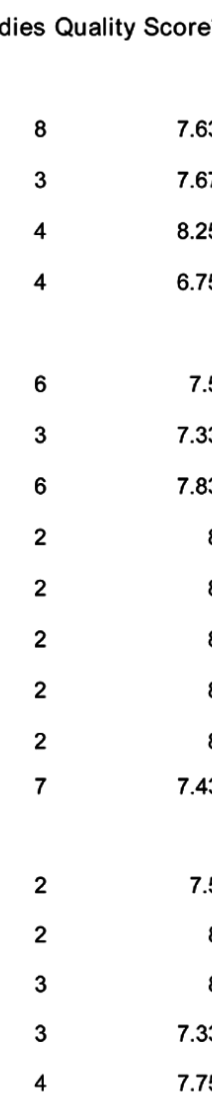

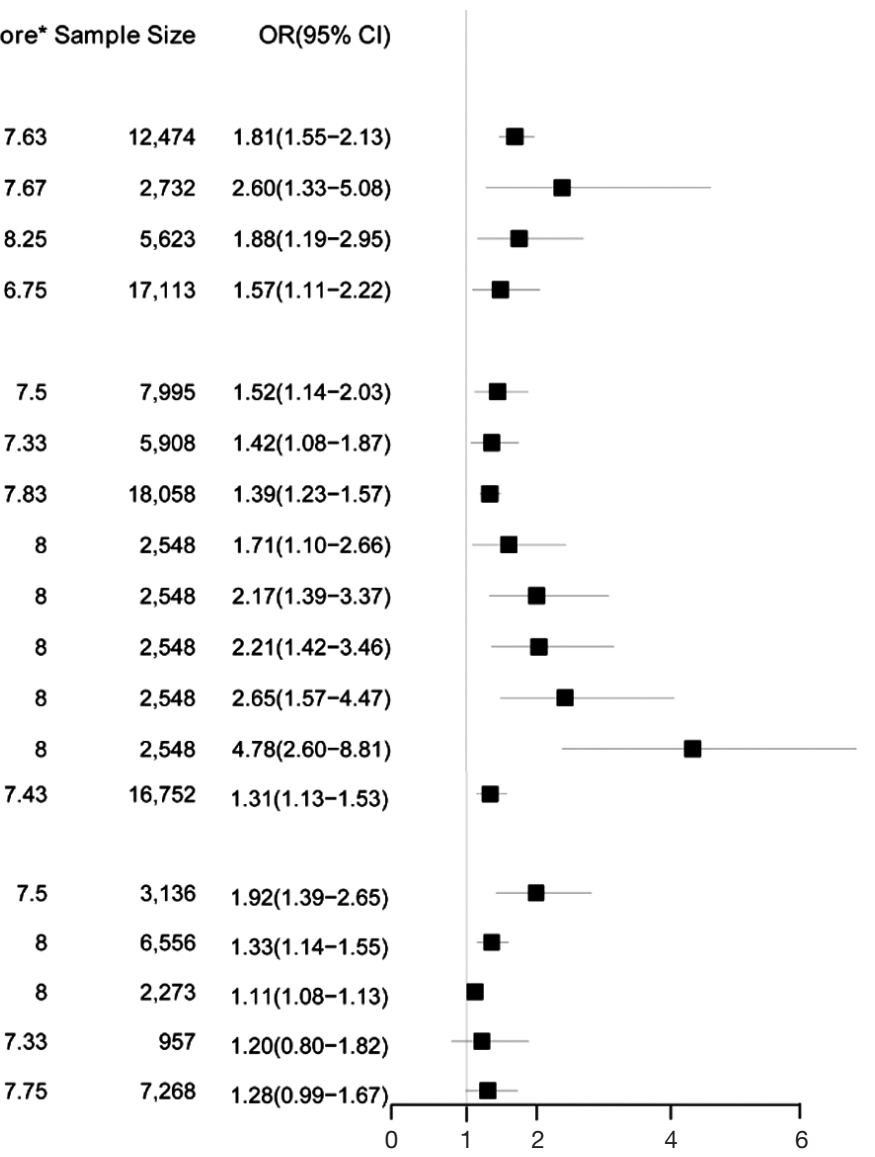

p Value I-squared

$\begin{array}{rr}0.28 & 19 \% \\ <0.01 & 84 \% \\ <0.01 & 78 \% \\ <0.01 & 84 \% \\ & \\ 0.03 & 59 \% \\ 0.33 & 9 \% \\ 0.36 & 8 \% \\ 0.64 & 0 \\ 0.48 & 0 \\ 0.56 & 0 \\ 0.3 & 8 \% \\ 0.36 & 0 \\ 0.74 & 0 \\ & \\ 0.56 & 0 \\ 0.85 & 0 \\ 0.46 & 0 \\ 0.34 & 6 \% \\ 0.22 & 32 \%\end{array}$

Figure 2 Forest plot shows the risk factors for carotid atherosclerosis in the meta-analysis. OR, odds ratio; 95\% CI, 95\% confidence interval. Quality Score*, mean quality score of included studies; ${ }^{\wedge}$ presence of carotid plaque; \# increased carotid intima-media thickness.

were pooled in the meta-analysis (Figure 2), which showed that hypertension could increase the risk of carotid plaque by $81 \%\left(\mathrm{OR}=1.81,95 \% \mathrm{CI}: 1.55-2.13, \mathrm{I}^{2}=19 \%, \mathrm{P}=0.28\right)$ (Figure S1). Three studies $(17,19,23)$ with 2,732 subjects exhibited hypertension has higher risk of increased CIMT $(\mathrm{OR}=2.60$, 95\% CI: $1.33-5.08, \mathrm{I}^{2}=84 \%, \mathrm{P}<0.01$ ) (Figure 22 ).

Additionally, it was indicated that the risk of plaque was significantly greater in people with increased systolic blood pressure (SBP) variability (every $10 \mathrm{mmHg}$ increase) and diastolic blood pressure (DBP) variability $(1,24,25)$. Pulse pressure (PP) variability (every $10 \mathrm{mmHg}$ increase) raises the risk of carotid plaque for both community-based subjects and stroke patients $(26,27)$.

\section{Diabetes mellitus}

Seven studies $(16,21-24,28,29)$ with 16,752 patients were included in the meta-analysis (Figure 2). The results showed that diabetics might have carotid plaque than non-diabetics
( $\mathrm{OR}=1.31,95 \%$ CI: $\left.1.13-1.53, \mathrm{I}^{2}=0 \%, \mathrm{P}=0.74\right)$ (Figure S3).

\section{Dyslipidemia}

The meta-analysis of ten studies (16,21-24,28,30-33) including 12,568 patients showed that patients with hyperlipidemia (OR $=1.92,95 \%$ CI: $1.39-2.65, \mathrm{I}^{2}=0, \mathrm{P}=0.56$ ), hypertriglyceridemia (triglyceride $\geq 1.7 \mathrm{mmol} / \mathrm{L}$ ) (OR $=1.33,95 \%$ CI: $\left.1.14-1.55, \mathrm{I}^{2}=0 \%, \mathrm{P}=0.85\right)$, and higher low density lipoprotein (low density lipoprotein $\geq 3.4 \mathrm{mmol} / \mathrm{L}$ ) ( $\mathrm{OR}=1.11,95 \%$ CI: $1.08-1.13, \mathrm{I}^{2}=0 \%, \mathrm{P}=0.46$ ) were more likely to have carotid plaque (Figures $S 4, S 5, S 6$ ). Moreover, there was strong likelihood of positive relationship between lower high density lipoprotein (high density lipoprotein $\leq 1.0 \mathrm{mmol} / \mathrm{L})\left(\mathrm{OR}=1.28,95 \%\right.$ CI: $\left.0.99-1.67, \mathrm{I}^{2}=32 \%, \mathrm{P}=0.22\right)$ or hypercholesterolemia (total cholesterol $\geq 5.2 \mathrm{mmol} / \mathrm{L}$ ) ( $\mathrm{OR}=1.20,95 \%$ CI: $\left.0.80-1.82, \mathrm{I}^{2}=6 \%, \mathrm{P}=0.34\right)$ with carotid plaque (Figures 57,58 ). One cohort study (34) indicated that hypercholesterolemia, hypertriglyceridemia, and 


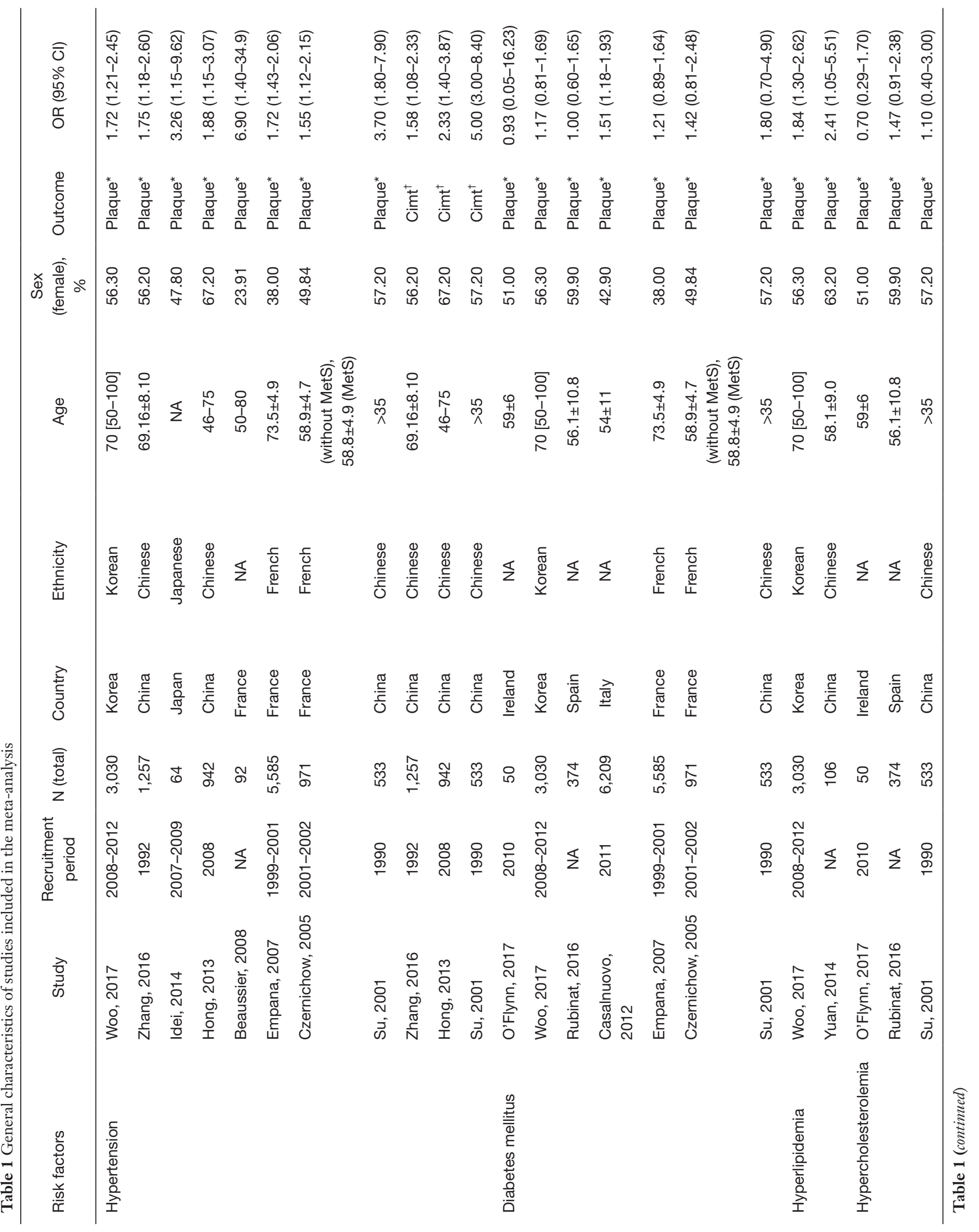




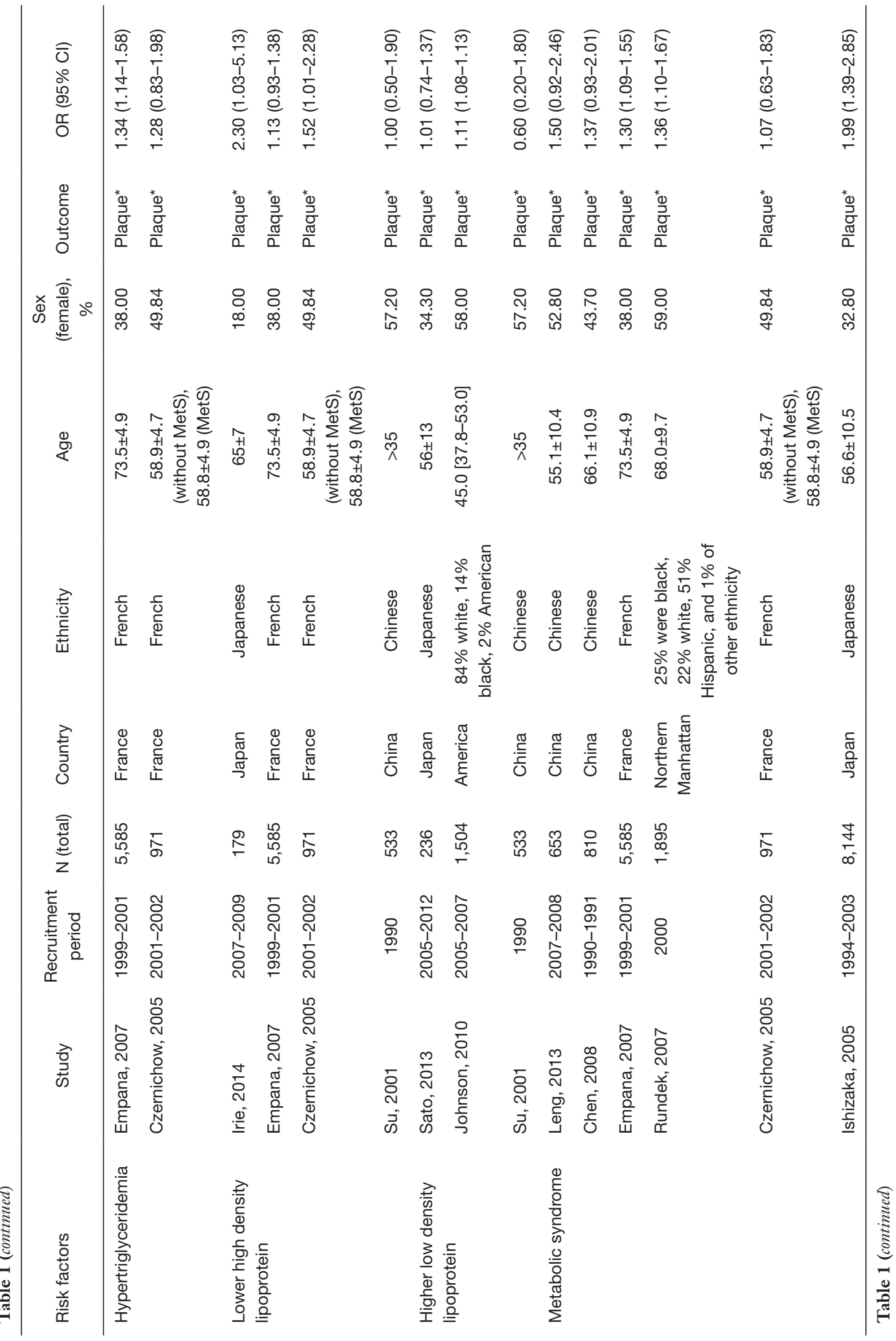




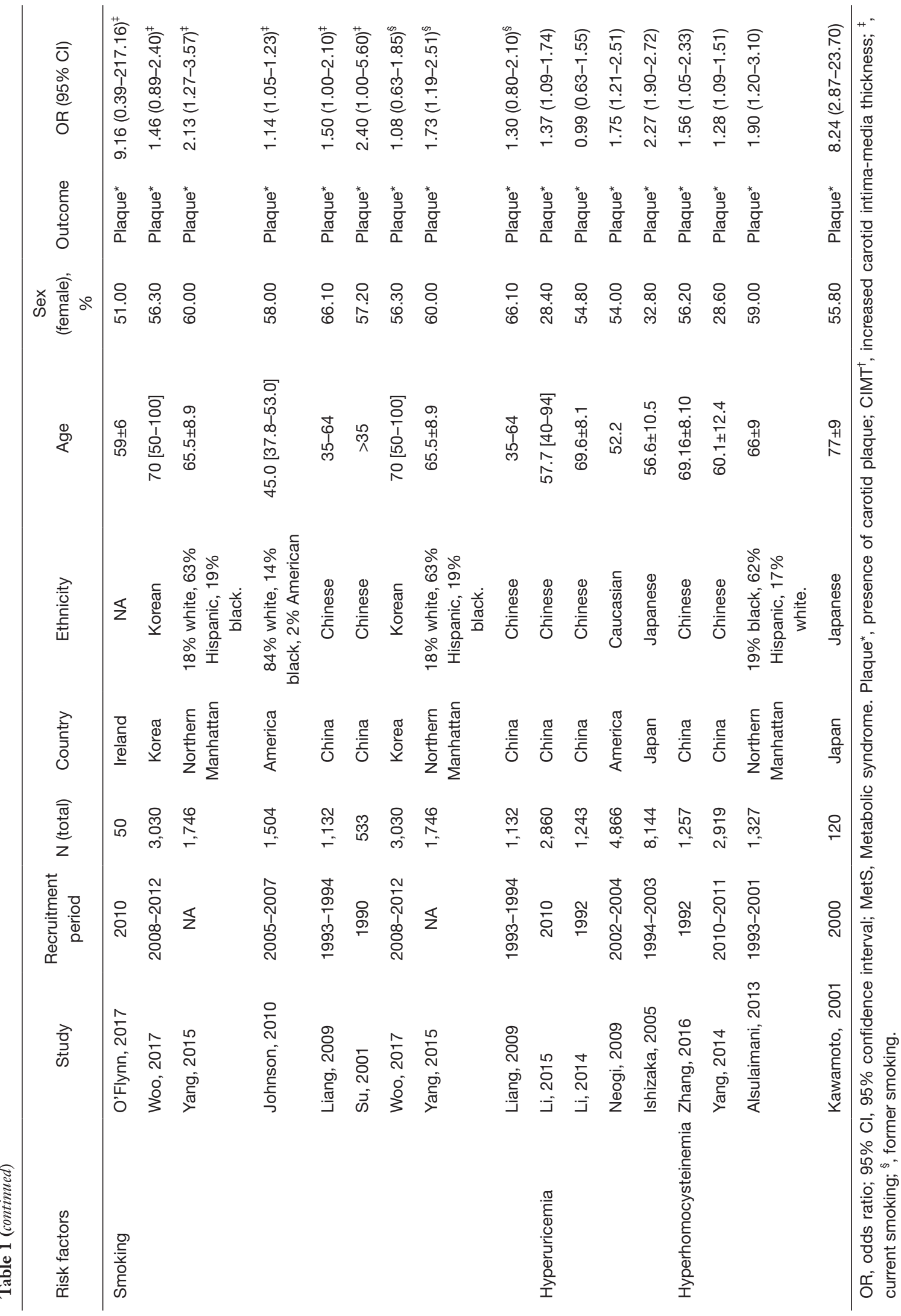


higher low density lipoprotein were risk factors for CIMT. Nevertheless, one cross-sectional study (33) failed to prove the relationship of total cholesterol (every $1 \mathrm{mmol} / \mathrm{L}$ increase) or triglyceride (every $1 \mathrm{mmol} / \mathrm{L}$ increase) with carotid plaque.

\section{Metabolic syndrome (MetS)}

MetS was defined according to the criteria of the National Cholesterol Education Program (NCEP) Adult Treatment Panel III (ATP-III) (35). Six studies $(21,22,36-39)$ including 18,058 individuals explored the association between MetS and carotid atherosclerosis, which showed that people with MetS might have more carotid plaque than non- MetS ( $\mathrm{OR}=1.39,95 \%$ CI: $1.23-1.57, \mathrm{I}^{2}=8 \%, \mathrm{P}=0.36$ ) (Figure S9). Notably, there was a dose-response relationship between the presence of carotid plaque and an increasing number of components of MetS (OR $=1.71,95 \%$ CI: 1.10-2.66, $\mathrm{I}^{2}=0 \%, \mathrm{P}=0.64$ for MetS-1; OR $=2.17,95 \%$ CI: $1.39-3.37$, $\mathrm{I}^{2}=0 \%, \mathrm{P}=0.48$ for MetS-2; OR $=2.21,95 \%$ CI: $1.42-3.46$, $\mathrm{I}^{2}=0 \%, \mathrm{P}=0.56$ for MetS-3; OR $=2.65,95 \%$ CI: $1.57-4.47$, $\mathrm{I}^{2}=8 \%, \mathrm{P}=0.30$ for MetS-4; OR $=4.78,95 \%$ CI: $2.60-8.81$, $\mathrm{I}^{2}=0 \%, \mathrm{P}=0.36$ for MetS-5) (Figures S10,S11,S12,S13,S14). Consistently, the association was confirmed by one cohort study (40) showing that individuals with MetS had higher risk of carotid plaque ( $\mathrm{HR}=1.92,95 \%$ CI: 1.06-3.47).

\section{Hyperuricemia}

The association between hyperuricemia (uric acid $\geq 420 \mu \mathrm{mol} / \mathrm{L}$ in man or uric acid $\geq 360 \mu \mathrm{mol} / \mathrm{L}$ in woman) and carotid plaque was reported in four studies $(25,39,41,42)$ including 17,113 participants. Pooled results indicated that hyperuricemia might increase the presence of plaque $\left(\mathrm{OR}=1.57,95 \% \mathrm{CI}\right.$ : $\left.1.11-2.22, \mathrm{I}^{2}=84 \%, \mathrm{P}<0.01\right)$ (Figure S15). Similarly, the increased CIMT was presented in those with higher uric acid level (OR $=1.24,95 \% \mathrm{CI}$ : 1.04-1.47) (43). Further, people with carotid plaque or stenosis were reported to have higher uric acid level. But another cross-sectional study (44) failed to find the relationship between uric acid and plaque.

\section{Hyperhomocysteinemia}

Four studies $(17,45-47)$ with 5,623 individuals were included and a significant positive relationship between hyperhomocysteinemia (homocysteine $\geq 15 \mu \mathrm{mol} / \mathrm{L}$ ) and carotid plaque was found ( $\mathrm{OR}=1.88,95 \%$ CI: 1.19-2.95, $\left.\mathrm{I}^{2}=78 \%, \mathrm{P}<0.01\right)$ (Figure S16). Additionally, one crosssectional study (48) found CIMT increased $0.06 \mathrm{~mm}$ as the level of homocysteine elevated per $1 \mu \mathrm{mol} / \mathrm{L}$.

\section{Smoking}

A pooled analysis of six studies $(16,23,24,30,49,50)$ including 7,995 participants indicated that smoking had a significant association with the risk of carotid plaque. Subgroup analyses showed that current smoking (current smokers vs. non-smokers, OR $=1.52,95 \%$ CI: $1.14-2.03, \mathrm{I}^{2}=59 \%$, $\mathrm{P}=0.03$ ) conferred greater risk than former smoking (former smokers vs. non-smokers, OR $=1.42,95 \%$ CI: $1.08-1.87$, $\left.\mathrm{I}^{2}=9 \%, \mathrm{P}=0.33\right)$ for the presence of carotid plaque (Figures S17,S18). Similarly, tobacco smoking is associated with increased CIMT, especially current smokers (51).

\section{Sensitivity analyses}

In sensitivity analyses (Table S4), the results were robust for hypertension, hyperhomocysteinemia, MetS, and hypercholesterolemia. For current smoking, the heterogeneity was reduced after omitting one study (30) without changing the significance of the results. For hyperuricemia, the pooled effect became non-significant (OR=1.50, 95\% CI: 0.95-2.38) after omitting one study (41) with different races.

\section{Assessment of publication bias}

For studies reporting the association between hypertension, diabetes mellitus, MetS, current smoking and the presence of carotid plaque, there was evidence of publication bias. After using the trim and fill method, the result barely changed for hypertension, diabetes mellitus, and MetS, but not for current smoking (Figure S19,S20,S21,S22,S23,S24,S25,S26).

\section{Others}

Some modifiable factors could not be included in the metaanalysis due to insufficient data, consisting of sexual abuse in early life $(52)$, air pollution $(53,54)$, socioeconomic strain (55-57), negative emotion (58-60), lifestyles (drinking, physical activity, and sleep duration) (5,61-64), diet (vitamin supplementation, egg consumption, vegetable intake and fish consumption) (65-72), medications (antihypertensive drugs, lipid-lowering drugs, and glucose-lowering drugs) (73-82), and pre-existing disease (OSAS) (apnea-hypopnea index $>15$ events/h) $(83,84)$ in mid-to-late life (Figure 3 and Table S5). 


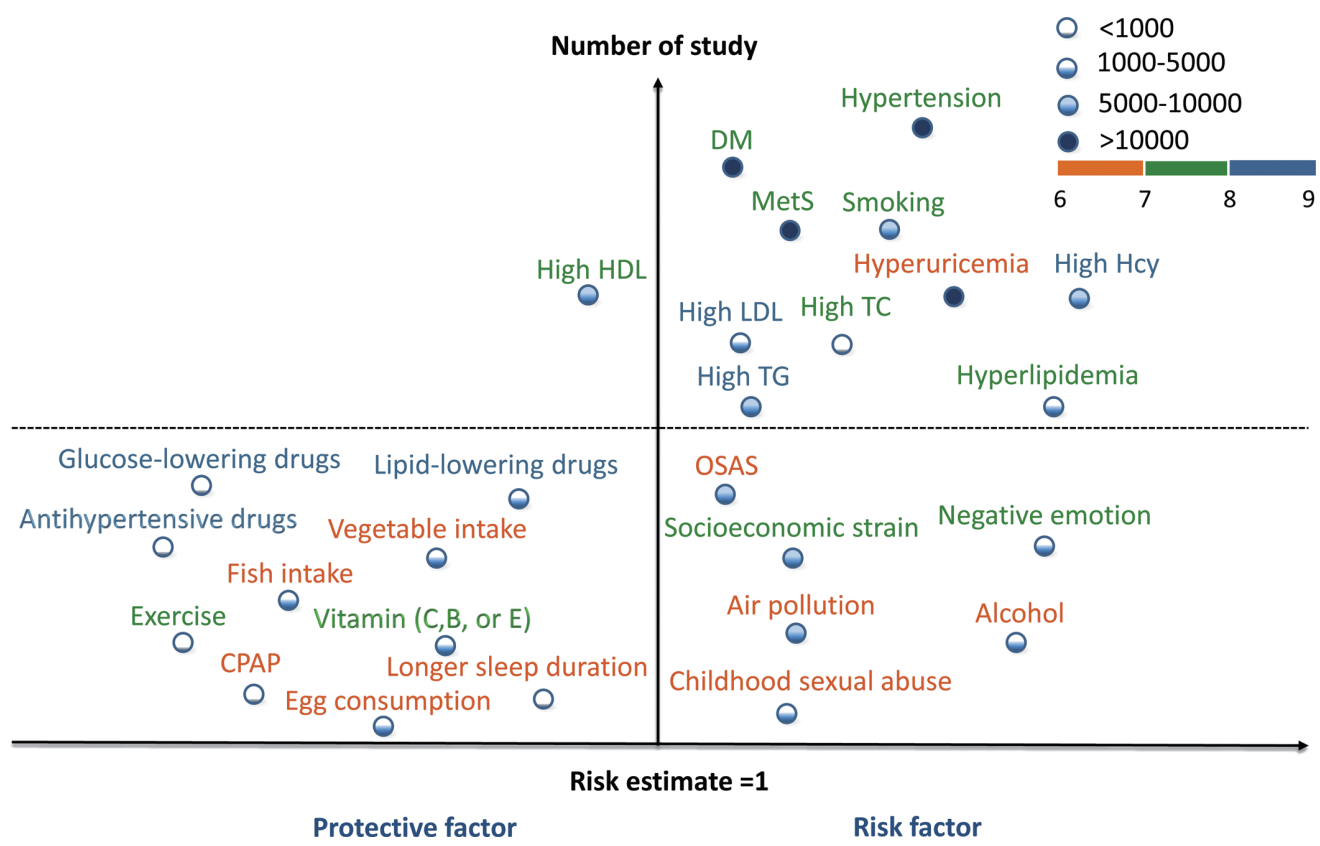

Figure 3 Factors showing significant positive and negative association with carotid atherosclerosis. DM, diabetes mellitus; MetS, metabolic syndrome; Hcy, homocysteine; HDL, how density lipoprotein; LDL, low density lipoprotein; TC, total cholesterol; TG, Triglyceride; OSAS, obstructive sleep apnea syndrome; CPAP, continuous positive airway pressure. Risk factors of meta-analysis are above the dotted line; Risk factors of systematic review are below the dotted line; The dots with four different filled ratios below risk factors represent different total sample size ranges; Different colors represent different quality score ranges.

\section{Discussion}

There were 27 studies included in the meta-analysis and 49 studies included in the systematic review. The meta-analysis suggested that dyslipidemia, hyperhomocysteinemia, hypertension, hyperuricemia, smoking, MetS, and diabetes mellitus could increase the risk of carotid plaque. Some low- and medium-quality references were included in the meta-analysis and systematic review; therefore, more highquality and large-scale prospective studies were needed to obtain more reliable results.

It is known that atherosclerosis affects other vascular beds before it causes significant carotid disease. The prevalence of carotid atherosclerosis and carotid plaque was $27.22 \%$ and $20.15 \%$ of Chinese people aged $30-79$ years in 2010 (85). Among patients with diagnosed coronary artery disease, $56.3 \%$ patients had raised CIMT, $74.8 \%$ patients had carotid plaques, and $8.4 \%$ patients had stenosis in carotid arteries (86). Patients with coronary artery disease more often had multiple plaques $(86.7 \%$ versus $13.8 \%$, $\mathrm{P}<0.001)(87)$. This suggests that coronary artery disease may be an early marker of carotid atherosclerosis.

MetS and its components were associated with both the presence and the progression of carotid atherosclerosis via multiple pathways. The association of hypertension with carotid atherosclerosis might be explained by hemodynamic changes which were related to the severity of CIMT (88). High plasma glucose levels could induce carotid structural changes by promoting endothelial dysfunction and vascular smooth muscle cell proliferation (8). Dyslipidemia might play an important role through the influx of lipids into the sites of vascular lesions. Interestingly, it was showed that higher high-density lipoprotein could reverse the transport of cholesterol and return it to the liver to protect against carotid atherosclerosis (89). The effect of triglyceride on carotid atherosclerosis was controversial because the criteria of hypertriglyceridemia were inconsistent. Recently, a large number of studies have been conducted to investigate whether drugs targeting comorbidities could reduce the incidence of carotid atherosclerosis. Some cohort studies showed that medications including antihypertensive drugs, lipid-lowering drugs and glucose-lowering drugs were protective against CIMT progression. The protective role of these drugs in atherosclerosis relies not only on their therapeutic effects on the pre-existing disease, but also on 
their direct protective effects on the arterial wall (75). A number of longitudinal studies showed that long-term use of lipid-lowering drugs for prevention of atherosclerosis might be more effective than short-term use $(78,90)$. Moreover, the results in our analysis were supportive of the roles of glucose-lowering drugs in preventing CIMT progression $(81,82,91)$. However, one cohort study showed no relationship between glucose-lowering drugs and the progression of CIMT, which could be explained either by insufficient follow-up or by the different inclusion criteria for people free from diabetes (80).

In addition, it was indicated that hyperuricemia could increase the occurrence of carotid plaque and accelerate CIMT progression through the production of reactive oxygen species, which could lead to oxidative stress and endothelial dysfunction (92). Besides, OSAS was reported to have a similar impact on carotid atherosclerosis (83), especially in rapid eye movement sleep (93), which may be attributed to nocturnal hypoxemia that could augment local inflammatory responses and exacerbate vessel damage in carotid arteries (94). Therefore, continuous positive airway pressure (CPAP) was considered the treatment for OSAS by ameliorating inflammation to protect against carotid atherosclerosis (95).

Negative emotion including depression, anger, and anxiety was identified as a risk factor for the progression of carotid atherosclerosis by many cohort studies $(58,96)$, which might be accounted for by sympathetic nervous system hyperreactivity, abnormalities in platelet function, hypercortisolemia, endothelial dysfunction, and heart rate variability (97). One cohort study (59) failed to prove that depression symptoms could increase the risk of CIMT, but the inconsistencies could be explained by threshold effect (depression $v s$. depression symptoms). The relationship between anger and CIMT was controversial according to different socioeconomic status (SES). People with low SES would have a greater likelihood of increased CIMT $(52,55,98)$. Business workers are considered to have higher CIMT when compare with factory workers (99). More evidence is required to explore the relationship between social, psychological condition and carotid atherosclerosis. Moreover, psychosocial interventions may play an important role in the prevention of carotid atherosclerosis.

Healthy lifestyles (e.g., no smoking, little drink and exercise) could protect against atherosclerosis through increasing endothelial dilatory factors and blood volume in the carotid artery. The mechanism for the influence of smoking on carotid atherosclerosis might be attributed to chronic inflammation which could damage endothelial cells exposed to circulating thrombogenic factors. These factors might increase macrophage infiltration and plaque thrombogenicity (49). One longitudinal study identified current smoking is related with extracranial carotid atherosclerosis but not with intracranial artery (100). Interestingly, if mothers smoked in pregnancy, children had thicker CIMT, and the impact was stronger if both parents smoked during pregnancy (101). Drinking could increase low density lipoprotein oxidation and oxidative stress to accelerate the progression of atherosclerosis when a man consumes alcohol over $40 \mathrm{~g} / \mathrm{d}$, and the CIMT progression had a dose-response relationship with alcohol intake, no matter what he drinks: beer, wine or spirits (102). Moderate exercise could increase antioxidant stress and anti-inflammatory processes, which could protect against the progression of carotid atherosclerosis (5). Shorter sleep duration may have higher CIMT in Western populations rather than Asian populations (103). More evidence is needed to confirm the association between sleep duration and carotid atherosclerosis.

Compared with a low-fat diet, a long-term use of the Mediterranean diet prevented the progression of carotid atherosclerosis in patients who were newly diagnosed with type 2 diabetes. Because Mediterranean diet is rich in vegetables and fish, which have beneficial effects on carotid via inhibition of oxidative stress (71). A number of cohort studies showed that vitamin supplementation (including vitamin $\mathrm{C}$, vitamin $\mathrm{B}$, or vitamin $\mathrm{E}$ ) could protect from CIMT progression, and it was speculated that the potential mechanism was the improved endothelial vasodilator function, but the effect might depend on dose (68). Vitamin B12 deficiency may increase the risk of carotid atherosclerosis by elevating total homocysteine (104), and vitamin B supplementation may slow the progression of carotid plaque burden by reducing homocysteine (105). Further longitudinal studies should be conducted to clarify the association between diet and carotid atherosclerosis.

\section{Strength and limitations}

As far as we know, this is the first meta-analysis and systematic review exploring the modifiable risk factors for carotid atherosclerosis. We tried to search all available studies and synthesise all suitable data.

Our study had a few limitations. First, our meta-analysis was based on cross-sectional studies, which could not reflect causal links between risk factors and carotid atherosclerosis. 
Hence, we carried out a systematic review based on the longitudinal studies. Second, as the analysis included observational studies, some unmeasured confounding factors and biases might exist. Therefore, the quality assessment of individual studies was carried out. Third, the number of population was relatively small for some risk factors, which should be clarified with caution. Fourth, there was publication bias when exploring the association between current smoking and the presence of carotid plaque, but the result was robust after sensitivity analyses. Therefore, the conclusion should be drawn with caution.

\section{Conclusions}

The current meta-analysis and systematic review indicated that pre-existing disease, negative emotion, lifestyle, and diet could increase the risk of carotid atherosclerosis, suggesting that these factors may serve as prevention targets. More investigation is needed to clarify the association of mood, lifestyle, and medication with carotid atherosclerosis. Further good-quality prospective studies are warranted.

\section{Acknowledgments}

Funding: This work was supported by grants from Taishan Scholars Program of Shandong Province (ts201511109 and tsqn20161079) and Qingdao Key Health Discipline Development Fund.

\section{Footnote}

Conflicts of Interest: The authors have no conflicts of interest to declare.

Ethical Statement: The authors are accountable for all aspects of the work in ensuring that questions related to the accuracy or integrity of any part of the work are appropriately investigated and resolved.

\section{References}

1. Jose PO,Frank AT,Kapphahn KI, et al. Cardiovascular disease mortality in Asian Americans. J Am Coll Cardiol 2014;64:2486-94.

2. Mehanna R, Jankovic J. Movement disorders in cerebrovascular disease. Lancet Neurol 2013;12:597-608.

3. Hankey GJ. Stroke. Lancet 2017;389:641-54.
4. Inaba Y, Chen JA, Bergmann SR. Carotid plaque, compared with carotid intima-media thickness, more accurately predicts coronary artery disease events: a metaanalysis. Atherosclerosis 2012;220:128-33.

5. Park J, Park H. Effects of 6 months of aerobic and resistance exercise training on carotid artery intima media thickness in overweight and obese older women. Geriatr Gerontol Int 2017;17:2304-10.

6. Maiorino MI, Bellastella G, Petrizzo M, et al. Effect of a Mediterranean diet on endothelial progenitor cells and carotid intima-media thickness in type 2 diabetes: Follow-up of a randomized trial. Eur J Prev Cardiol 2017;24:399-408.

7. Munger MA, Hawkins DW. Atherothrombosis: epidemiology, pathophysiology, and prevention. J Am Pharm Assoc (2003) 2004;44:S5-12; quiz S-3.

8. Kozakova M, Natali A, Dekker J, et al. Insulin sensitivity and carotid intima-media thickness: relationship between insulin sensitivity and cardiovascular risk study. Arterioscler Thromb Vasc Biol 2013;33:1409-17.

9. Peña AS, Maftei O, Harrington J, et al. Lack of evidence for progression of atherosclerosis during puberty in type 1 diabetes. Pediatr Diabetes 2016;17:199-205.

10. Moher D, Liberati A, Tetzlaff J, et al. Preferred reporting items for systematic reviews and meta-analyses: The PRISMA statement. International Journal of Surgery 2010;8:336-41.

11. Guise JM, Chang C, Viswanathan M, et al. Agency for Healthcare Research and Quality Evidence-based Practice Center methods for systematically reviewing complex multicomponent health care interventions. J Clin Epidemiol 2014;67:1181-91.

12. Higgins JP, Thompson SG. Quantifying heterogeneity in a meta-analysis. Stat Med 2002;21:1539-58.

13. DerSimonian R, Laird N. Meta-analysis in clinical trials. Control Clin Trials 1986;7:177-88.

14. Higgins JP, Thompson SG, Deeks JJ, et al. Measuring inconsistency in meta-analyses. BMJ 2003;327:557-60.

15. Duval S, Tweedie R. Trim and fill: A simple funnel-plotbased method of testing and adjusting for publication bias in meta-analysis. Biometrics 2000;56:455-63.

16. Woo SY, Joh JH, Han SA, et al. Prevalence and risk factors for atherosclerotic carotid stenosis and plaque: A population-based screening study. Medicine (Baltimore) 2017;96:e5999.

17. Zhang Z, Fang X, Hua Y, et al. Combined Effect of Hyperhomocysteinemia and Hypertension on the Presence of Early Carotid Artery Atherosclerosis. J Stroke 
Cerebrovasc Dis 2016;25:1254-62.

18. Idei M, Hirayama S, Miyake N, et al. Mean postprandial triglyceride concentration is an independent risk factor for carotid atherosclerosis in patients with type 2 diabetes. Clin Chim Acta 2014;430:134-9.

19. Hong H, Wang H, Liao H. Prehypertension is associated with increased carotid atherosclerotic plaque in the community population of Southern China. BMC cardiovascular disorders, 2013;13:20.

20. Beaussier H, Masson I, Collin C, et al. Carotid plaque, arterial stiffness gradient, and remodeling in hypertension. Hypertension 2008;52:729-36.

21. Empana JP, Zureik M, Gariepy J, et al. The metabolic syndrome and the carotid artery structure in noninstitutionalized elderly subjects: the three-city study. Stroke 2007;38:893-9.

22. Czernichow S, Bertrais S, Blacher J, et al. Metabolic syndrome in relation to structure and function of large arteries: a predominant effect of blood pressure. A report from the SU.VI.MAX. Vascular Study. Am J Hypertens 2005;18:1154-60.

23. Su TC, Jeng JS, Chien KL, et al. Hypertension status is the major determinant of carotid atherosclerosis: a communitybased study in Taiwan. Stroke 2001;32:2265-71.

24. O'Flynn AM, Ho E, Dolan E, et al. The association of night-time systolic blood pressure with ultrasound markers of subclinical cardiac and vascular disease. Blood Press Monit 2017;22:18-26.

25. Li Y, Lu J, Wu X, et al. Serum uric acid concentration and asymptomatic hyperuricemia with subclinical organ damage in general population. Angiology 2014;65:634-40.

26. Lovett JK, Howard SC, Rothwell PM. Pulse pressure is independently associated with carotid plaque ulceration. J Hypertens 2003;21:1669-76.

27. Cheng CA, Chien WC, Hsu CY, et al. Risk analysis of carotid stent from a population-based database in Taiwan. Medicine (Baltimore) 2016;95:e4747.

28. Rubinat E, Marsal JR, Vidal T, et al. Subclinical Carotid Atherosclerosis in Asymptomatic Subjects With Type 2 Diabetes Mellitus. J Cardiovasc Nurs 2016;31:E1-7.

29. Casalnuovo G, Gerdts E, de Simone G, et al. Arterial stiffness is associated with carotid atherosclerosis in hypertensive patients (the Campania Salute Network). Am J Hypertens 2012;25:739-45.

30. Johnson HM, Piper ME, Jorenby DE, et al. Risk factors for subclinical carotid atherosclerosis among current smokers. Prev Cardiol 2010;13:166-71.

31. Yuan C, Lai CW, Chan LW, et al. Cumulative effects of hypertension, dyslipidemia, and chronic kidney disease on carotid atherosclerosis in Chinese patients with type 2 diabetes mellitus. J Diabetes Res 2014;2014:179686.

32. Irie $Y$, Katakami N, Kaneto H, et al. The risk factors associated with ultrasonic tissue characterization of carotid plaque in type 2 diabetic patients. J Diabetes Complications 2014;28:523-7.

33. Sato Y, Nagao M, Asai A, et al. Association of glycated albumin with the presence of carotid plaque in patients with type 2 diabetes. J Diabetes Investig 2013;4:634-9.

34. Huang Y, Yu X, Millican D, et al. The measurement of lipids currently and 9 years ago--which is more associated with carotid intima-media thickness? Clin Cardiol 2012;35:512-7.

35. James IC. Executive Summary of the Third Report of the National Cholesterol Education Program (NCEP) Expert Panel on Detection, Evaluation, and Treatment of High Blood Cholesterol in Adults (Adult Treatment Panel III). JAMA 2001;285:2486-97.

36. Leng XY, Chen XY, Chook P, et al. Association between metabolic syndrome and carotid atherosclerosis: a community-based study in Hong Kong. Metab Syndr Relat Disord 2013;11:109-14.

37. Chen PC, Chien KL, Hsu HC, et al. C-reactive protein and the metabolic syndrome correlate differently with carotid atherosclerosis between men and women in a Taiwanese community. Metabolism 2008;57:1023-8.

38. Rundek T, White H, Boden-Albala B, et al. The metabolic syndrome and subclinical carotid atherosclerosis: the Northern Manhattan Study. J Cardiometab Syndr 2007;2:24-9.

39. Ishizaka N, Ishizaka $\mathrm{Y}$, Toda $\mathrm{E}$, et al. Association between serum uric acid, metabolic syndrome, and carotid atherosclerosis in Japanese individuals. Arterioscler Thromb Vasc Biol 2005;25:1038-44.

40. Jung JM, Young Kwon D, Han C, et al. Metabolic syndrome and early carotid atherosclerosis in the elderly. J Atheroscler Thromb 2014;21:435-44.

41. Neogi T, Ellison RC, Hunt S, et al. Serum uric acid is associated with carotid plaques: the National Heart, Lung, and Blood Institute Family Heart Study. J Rheumatol 2009;36:378-84.

42. Li Q, Zhou Y, Dong K, et al. The Association between Serum Uric Acid Levels and the Prevalence of Vulnerable Atherosclerotic Carotid Plaque: A Cross-sectional Study. Sci Rep 2015;5:10003.

43. Zhang Z, Bian L, Choi Y. Serum uric acid: a marker of metabolic syndrome and subclinical atherosclerosis in 
Korean men. Angiology 2012;63:420-8.

44. Oikonen M, Wendelin-Saarenhovi M, Lyytikainen LP, et al. Associations between serum uric acid and markers of subclinical atherosclerosis in young adults. The cardiovascular risk in Young Finns study. Atherosclerosis 2012;223:497-503.

45. Yang X, Zhou Y, Liu C, et al. Homocysteine and carotid plaque stability: a cross-sectional study in Chinese adults. PLoS One 2014;9:e94935.

46. Alsulaimani S, Gardener H, Elkind MS, et al. Elevated homocysteine and carotid plaque area and densitometry in the Northern Manhattan Study. Stroke 2013;44:457-61.

47. Kawamoto R, Doi T, Tokunaga H. Association of plasma homocysteine concentrations with carotid atherosclerosis in elderly Japanese. Intern Med 2001;40:1189-94.

48. Nakhai-Pour HR, Grobbee DE, Bots ML, et al. Circulating homocysteine and large arterial stiffness and thickness in a population-based sample of middle-aged and elderly men. J Hum Hypertens 2007;21:942-8.

49. Yang D, Iyer S, Gardener H, et al. Cigarette Smoking and Carotid Plaque Echodensity in the Northern Manhattan Study. Cerebrovasc Dis 2015;40:136-43.

50. Liang LR, Wong ND, Shi P, et al. Cross-sectional and longitudinal association of cigarette smoking with carotid atherosclerosis in Chinese adults. Prev Med 2009;49:62-7.

51. Kianoush S, Yakoob MY, Al-Rifai M, et al. Associations of Cigarette Smoking With Subclinical Inflammation and Atherosclerosis: ELSA-Brasil (The Brazilian Longitudinal Study of Adult Health). J Am Heart Assoc 2017;6:e005088.

52. Thurston RC, Chang Y, Derby CA, et al. Abuse and subclinical cardiovascular disease among midlife women: the study of women's health across the nation. Stroke 2014;45:2246-51.

53. Wang Y, Wellenius GA, Hickson DA, et al. Residential Proximity to Traffic-Related Pollution and Atherosclerosis in 4 Vascular Beds Among African-American Adults: Results From the Jackson Heart Study. Am J Epidemiol 2016;184:732-43.

54. Painschab MS, Davila-Roman VG, Gilman RH, et al. Chronic exposure to biomass fuel is associated with increased carotid artery intima-media thickness and a higher prevalence of atherosclerotic plaque. Heart 2013;99:984-91.

55. Thurston RC, El Khoudary SR, Derby CA, et al. Low socioeconomic status over 12 years and subclinical cardiovascular disease: the study of women's health across the nation. Stroke 2014;45:954-60.

56. Hintsanen M, Kivimaki M, Elovainio M, et al. Job strain and early atherosclerosis: the Cardiovascular Risk in Young Finns study. Psychosom Med 2005;67:740-7.

57. Peterson LM, Matthews KA, Derby CA, et al. The relationship between cumulative unfair treatment and intima media thickness and adventitial diameter: The moderating role of race in the study of women's health across the nation. Health Psychol 2016;35:313-21.

58. Haas DC, Davidson KW, Schwartz DJ, et al. Depressive symptoms are independently predictive of carotid atherosclerosis. Am J Cardiol 2005;95:547-50.

59. Rice SC, Zonderman AB, Metter EJ, et al. Absence of relation between depressive symptoms and carotid intimal medial thickness in the Baltimore Longitudinal Study of Aging. Psychosom Med 2009;71:70-6.

60. Tiemeier H, van Dijck W, Hofman A, et al. Relationship between atherosclerosis and late-life depression: the Rotterdam Study. Arch Gen Psychiatry 2004;61:369-76.

61. Sands MR, Lauderdale DS, Liu K, et al. Short sleep duration is associated with carotid intima-media thickness among men in the Coronary Artery Risk Development in Young Adults (CARDIA) Study. Stroke 2012;43:2858-64.

62. Kozàkovà M, Palombo C, Morizzo C, et al. Effect of sedentary behaviour and vigorous physical activity on segment-specific carotid wall thickness and its progression in a healthy population. Eur Heart J 2010;31:1511-9.

63. Lee YH, Shin MH, Kweon SS, et al. Alcohol consumption and carotid artery structure in Korean adults aged 50 years and older. BMC Public Health 2009;9:358.

64. Debette S, Courbon D, Leone N, et al. Tea consumption is inversely associated with carotid plaques in women. Arterioscler Thromb Vasc Biol 2008;28:353-9.

65. Goldberg S, Gardener H, Tiozzo E, et al. Egg consumption and carotid atherosclerosis in the Northern Manhattan study. Atherosclerosis 2014;235:273-80.

66. Buscemi S, Nicolucci A, Mattina A, et al. Association of dietary patterns with insulin resistance and clinically silent carotid atherosclerosis in apparently healthy people. Eur J Clin Nutr 2013;67:1284-90.

67. Kesse-Guyot E, Vergnaud AC, Fezeu L, et al. Associations between dietary patterns and arterial stiffness, carotid artery intima-media thickness and atherosclerosis. Eur J Cardiovasc Prev Rehabil 2010;17:718-24.

68. Zureik M, Galan P, Bertrais S, et al. Effects of long-term daily low-dose supplementation with antioxidant vitamins and minerals on structure and function of large arteries. Arterioscler Thromb Vasc Biol 2004;24:1485-91.

69. Thoenes M, Oguchi A, Nagamia S, et al. The effects of extended-release niacin on carotid intimal media 
thickness, endothelial function and inflammatory markers in patients with the metabolic syndrome. Int J Clin Pract 2007;61:1942-8.

70. Bondonno CP, Blekkenhorst LC, Prince RL, et al. Association of Vegetable Nitrate Intake With Carotid Atherosclerosis and Ischemic Cerebrovascular Disease in Older Women. Stroke 2017;48:1724-9.

71. Blekkenhorst LC, Bondonno CP, Lewis JR, et al. Cruciferous and Total Vegetable Intakes Are Inversely Associated With Subclinical Atherosclerosis in Older Adult Women. J Am Heart Assoc 2018;7:e008391.

72. Johnsen SH, Jacobsen BK, Braekkan SK, et al. Fish consumption, fish oil supplements and risk of atherosclerosis in the Tromso study. Nutr J 2018;17:56.

73. Ramadan R, Dhawan SS, Binongo JN, et al. Effect of Angiotensin II Type I Receptor Blockade with Valsartan on Carotid Artery Atherosclerosis: A Double Blind Randomized Clinical Trial Comparing Valsartan and Placebo (EFFERVESCENT). Am Heart J 2016;174:68-79.

74. Wikstrand J, Berglund G, Hedblad B, et al. Antiatherosclerotic effects of beta-blockers. Am J Cardiol 2003;91:25H-9H.

75. Hosomi N, Mizushige K, Ohyama H, et al. Angiotensinconverting enzyme inhibition with enalapril slows progressive intima-media thickening of the common carotid artery in patients with non-insulin-dependent diabetes mellitus. Stroke 2001;32:1539-45.

76. Meuwese MC, de Groot E, Duivenvoorden R, et al. ACAT inhibition and progression of carotid atherosclerosis in patients with familial hypercholesterolemia: the CAPTIVATE randomized trial. JAMA 2009;301:1131-9.

77. Yamagami H, Sakaguchi M, Furukado S, et al. Statin therapy increases carotid plaque echogenicity in hypercholesterolemic patients. Ultrasound Med Biol 2008;34:1353-9.

78. Bots ML, Palmer MK, Dogan S, et al. Intensive lipid lowering may reduce progression of carotid atherosclerosis within 12 months of treatment: the METEOR study. J Intern Med 2009;265:698-707.

79. Patel YR, Kirkman MS, Considine RV, et al. Effect of acarbose to delay progression of carotid intima-media thickness in early diabetes. Diabetes Metab Res Rev 2013;29:582-91.

80. Christoph M, Herold J, Berg-Holldack A, et al. Effects of the Peroxisome Proliferator-Activated Receptor-gamma Agonist Pioglitazone on Peripheral Vessel Function and Clinical Parameters in Nondiabetic Patients: A DoubleCenter, Randomized Controlled Pilot Trial. Cardiology
2015;131:165-71.

81. Hanefeld M, Chiasson JL, Koehler C, et al. Acarbose slows progression of intima-media thickness of the carotid arteries in subjects with impaired glucose tolerance. Stroke 2004;35:1073-8.

82. Mita T, Watada H, Shimizu T, et al. Nateglinide reduces carotid intima-media thickening in type 2 diabetic patients under good glycemic control. Arterioscler Thromb Vasc Biol 2007;27:2456-62.

83. Gunnarsson SI, Peppard PE, Korcarz CE, et al. Obstructive sleep apnea is associated with future subclinical carotid artery disease: thirteen-year follow-up from the Wisconsin sleep cohort. Arterioscler Thromb Vasc Biol 2014;34:2338-42.

84. Fox N, Ayas N, Park JE, et al. Carotid intima media thickness in patients with obstructive sleep apnea: comparison with a community-based cohort. Lung 2014;192:297-303.

85. Song $\mathrm{P}, \mathrm{Xia} \mathrm{W}, \mathrm{Zhu} \mathrm{Y}$, et al. Prevalence of carotid atherosclerosis and carotid plaque in Chinese adults: A systematic review and meta-regression analysis. Atherosclerosis 2018;276:67-73.

86. Sahadevan M, Chee KH, Tai M-LS. Prevalence of extracranial carotid atherosclerosis in the patients with coronary artery disease in a tertiary hospital in Malaysia. Medicine 2019;98:e15082.

87. Kozlov S, Balachonova T, Machmudova H, et al. Carotid Atherosclerosis, Endothelial Disfunction, and Arterial Stiffness in Young and Middle-Aged Men with Coronary Artery Disease. International Journal of Vascular Medicine 2012;2012:950130.

88. Chien KL, Tu YK, Hsu HC, et al. Differential effects of the changes of LDL cholesterol and systolic blood pressure on the risk of carotid artery atherosclerosis. BMC Cardiovasc Disord 2012;12:66.

89. Gardener H, Della Morte D, Elkind MS, et al. Lipids and carotid plaque in the Northern Manhattan Study (NOMAS). BMC Cardiovasc Disord 2009;9:55.

90. Herder M, Arntzen KA, Johnsen SH, et al. Longterm use of lipid-lowering drugs slows progression of carotid atherosclerosis: the Tromso study 1994 to 2008. Arterioscler Thromb Vasc Biol 2013;33:858-62.

91. Yamasaki Y, Katakami N, Furukado S, et al. Longterm effects of pioglitazone on carotid atherosclerosis in Japanese patients with type 2 diabetes without a recent history of macrovascular morbidity. J Atheroscler Thromb 2010;17:1132-40.

92. Bae JS, Shin DH, Park PS, et al. The impact of serum uric 
acid level on arterial stiffness and carotid atherosclerosis: the Korean Multi-Rural Communities Cohort study. Atherosclerosis 2013;231:145-51.

93. Ljunggren M, Lindberg E, Franklin KA, et al. Obstructive sleep apnea during rapid eye movement sleep is associated with early signs of atherosclerosis in women. Sleep 2018;41. doi: 10.1093/sleep/zsy099.

94. Kim J, Pack A, Maislin G, et al. Prospective observation on the association of snoring with subclinical changes in carotid atherosclerosis over four years. Sleep Med 2014;15:769-75.

95. Kostopoulos K, Alhanatis E, Pampoukas K, et al. CPAP therapy induces favorable short-term changes in epicardial fat thickness and vascular and metabolic markers in apparently healthy subjects with obstructive sleep apnea-hypopnea syndrome (OSAHS). Sleep Breath 2016;20:483-93.

96. Paterniti S, Zureik M, Ducimetiere P, et al. Sustained anxiety and 4-year progression of carotid atherosclerosis. Arterioscler Thromb Vasc Biol 2001;21:136-41.

97. Elovainio M, Keltikangas-Jarvinen L, Kivimaki M, et al. Depressive symptoms and carotid artery intima-media thickness in young adults: the Cardiovascular Risk in Young Finns Study. Psychosom Med 2005;67:561-7.

98. Ranjit N, Diez-Roux AV, Chambless L, et al. Socioeconomic differences in progression of carotid intima-media thickness in the Atherosclerosis Risk in Communities study. Arterioscler Thromb Vasc Biol

Cite this article as: Ji X, Leng XY, Dong Y, Ma YH, Xu W, Cao XP, Hou XH, Dong Q, Tan L, Yu JT. Modifiable risk factors for carotid atherosclerosis: a meta-analysis and systematic review. Ann Transl Med 2019;7(22):632. doi: 10.21037/atm.2019.10.115
2006;26:411-6.

99. Garshick M, Wu F, Demmer R, et al. The association between socioeconomic status and subclinical atherosclerosis in a rural Bangladesh population. Preventive Medicine 2017;102:6-11.

100.Ji R, Pan Y, Yan H, et al. Current smoking is associated with extracranial carotid atherosclerotic stenosis but not with intracranial large artery disease. BMC Neurology 2017;17:120.

101. West HW, Juonala M, Gall SL, et al. Exposure to parental smoking in childhood is associated with increased risk of carotid atherosclerotic plaque in adulthood: the Cardiovascular Risk in Young Finns Study. Circulation 2015;131:1239-46.

102. Kauhanen J, Kaplan GA, Goldberg DE, et al. Pattern of alcohol drinking and progression of atherosclerosis. Arterioscler Thromb Vasc Biol 1999;19:3001-6.

103. Suzuki S, Arima H, Miyazaki S, et al. Self-reported Sleep Duration and Subclinical Atherosclerosis in a General Population of Japanese Men. J Atheroscler Thromb 2018;25:186-98.

104. Robertson J, Iemolo F, Stabler SP, et al. Vitamin B12, homocysteine and carotid plaque in the era of folic acid fortification of enriched cereal grain products. CMAJ 2005;172:1569-73.

105.Peterson JC, Spence JD. Vitamins and progression of atherosclerosis in hyper-homocyst(e)inaemia. Lancet 1998;351:263. 
[PubMed]

\section{Retrieval strategy}

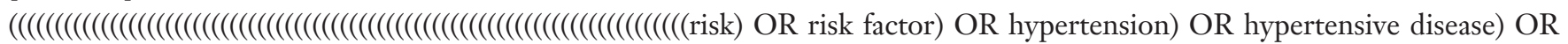
blood pressure) OR BP) OR systolic blood pressure) OR SBP) OR diastolic blood pressure) OR DBP) OR diabetes) OR diabetes mellitus) OR DM) OR hyperglycemia) OR hyperlipidemia) OR hyperlipaemia) OR dyslipidemia) OR triglyceride) OR TG) OR high density lipoprotein) OR HDL) OR low density lipoprotein) OR LDL) OR cholesterin) OR cholesterol) OR hypercholesterolemia) OR apolipoprotein) OR Apo) OR BMI) OR body mass index) OR overweight) OR overload) OR obesity) OR high weight circumference) OR fat) OR adiposis) OR corpulence) OR metabolic syndrome) OR Mets) OR metabolic dysfunction) OR metabolic disorder) OR metabolic disturbance) OR smoking) OR smoke) OR smoker) OR tabacco) OR nicotine addiction) OR uric acid) OR UA) OR hyperuricemia) OR hyperuricaemia) OR homocysteine) OR HCY) OR homocystinemia) OR diet) OR food) OR wine) OR alcohol) OR drinking) OR drink) OR drinker) OR vitamin) OR niacin) OR nicotinic acid) OR folic acid) OR folate) OR folacin) OR cobalamin) OR sport) OR exercise) OR movement) OR activity)) AND (carotid)) AND (((((prospective) OR cohort) OR follow) OR longitudinal) OR nested case-control) 
Table S1 The quality evaluation of cross-sectional studies by agency for healthcare research and quality (AHRQ)

\begin{tabular}{|c|c|c|c|c|c|c|c|c|c|c|c|c|}
\hline Study & $\begin{array}{l}\text { Define the source } \\
\text { of information } \\
\text { (survey, record } \\
\text { review) }\end{array}$ & $\begin{array}{l}\text { List inclusion and exclusion criteria } \\
\text { for exposed and unexposed } \\
\text { subjects (cases and controls) or } \\
\text { refer to previous publications }\end{array}$ & $\begin{array}{l}\text { Indicate time } \\
\text { period used } \\
\text { for identifying } \\
\text { patients }\end{array}$ & $\begin{array}{l}\text { Indicate whether or } \\
\text { not subjects were } \\
\text { consecutive if not } \\
\text { population-based }\end{array}$ & $\begin{array}{l}\text { Indicate if evaluators of } \\
\text { subjective components of study } \\
\text { were masked to other aspects of } \\
\text { the status of the participants }\end{array}$ & $\begin{array}{l}\text { Describe any assessments } \\
\text { undertaken for quality assurance } \\
\text { purposes (e.g., test/retest of } \\
\text { primary outcome measurements) }\end{array}$ & $\begin{array}{l}\text { Explain } \\
\text { any patient } \\
\text { exclusions } \\
\text { from analysis }\end{array}$ & $\begin{array}{l}\text { Describe how } \\
\text { confounding was } \\
\text { assessed and/or } \\
\text { controlled }\end{array}$ & $\begin{array}{l}\text { If applicable, explain } \\
\text { how missing data } \\
\text { were handled in the } \\
\text { analysis }\end{array}$ & $\begin{array}{l}\text { Summarize patient } \\
\text { response rates and } \\
\text { completeness of } \\
\text { data collection }\end{array}$ & $\begin{array}{l}\text { Clarify what follow-up, if any, was } \\
\text { expected and the percentage of } \\
\text { patients for which incomplete } \\
\text { data or follow-up was obtained }\end{array}$ & $\begin{array}{l}\text { Total } \\
\text { score }\end{array}$ \\
\hline Blekkenhorst, 2018 & 放 & is & is & & is & & is & का & & है & is & 8 \\
\hline Bondonno, 2018 & is & is & is & & is & & is & is & & is & is & 8 \\
\hline Johnsen, 2018 & is & is & is & & is & & is & is & & 动 & 动 & 8 \\
\hline Kianoush, 2017 & is & is & is & & is & is & is & is & & is & is & 9 \\
\hline Woo, 2017 & is & & is & th & is & & & th & & is & is & 7 \\
\hline O'Flynn, 2017 & th & & is & is & is & & & is & & th & is & 7 \\
\hline Rubinat, 2016 & is & & is & is & is & & & is & & is & th & 7 \\
\hline Cheng, 2016 & is & is & is & & is & & is & is & & is & & 7 \\
\hline Zhang, 2016 & is & is & is & is & is & & & is & & 弥 & is & 8 \\
\hline Li, 2015 & is & is & is & is & 虾 & & & 动 & & & 动 & 7 \\
\hline Yang, 2015 & is & 动 & & 弥 & & 动 & & 动 & & 访 & 动 & 6 \\
\hline Yang, 2014 & 动 & 动 & is & 动 & is & & & 动 & & is & 动 & 8 \\
\hline Li, 2014 & 动 & & is & 动 & is & & & 动 & & is & 动 & 7 \\
\hline Yuan, 2014 & 动 & 动 & is & 动 & 放 & & & 动 & & is & 动 & 8 \\
\hline Fox, 2014 & 动 & & 为 & 动 & is & & & is & & is & & 6 \\
\hline Irie, 2014 & 的 & 放 & is & & & & is & 访 & & is & 动 & 7 \\
\hline Idei, 2014 & 虾 & & is & 虾 & 虾 & & & is & & 虾 & is & 7 \\
\hline Painschab, 2013 & is & & is & & & is & is & & & is & & 5 \\
\hline Sato, 2013 & is & is & is & is & is & & & is & & is & is & 8 \\
\hline Hong, 2013 & is & & is & 动 & is & & & is & & is & is & 7 \\
\hline Alsulaimani, .2013 & is & 动 & is & 动 & is & & & 动 & & is & 动 & 8 \\
\hline Buscemi, 2013 & 象 & & is & & & & कर & 动 & & 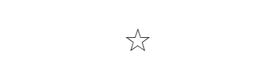 & & 5 \\
\hline Leng, 2013 & 虾 & & is & $\Leftrightarrow$ & 虾 & & & is & & 虾 & is & 7 \\
\hline Oikonen, 2012 & 动 & & 动 & 动 & is & & 动 & 动 & & 动 & 动 & 8 \\
\hline Casalnuovo, 2012 & 动 & & is & is & is & & & is & & is & is & 7 \\
\hline Zhang, 2012 & 虹 & 动 & 论 & is & & & & 动 & & & & 5 \\
\hline Sands, 2012 & 动 & is & is & & & & & 动 & & 放 & & 5 \\
\hline Johnson, 2010 & is & is & 动 & is & is & & & th & & is & is & 8 \\
\hline Kozakova, 2010 & is & is & is & th & is & is & is & th & & th & & 9 \\
\hline Gardener, 2009 & is & th & & is & & & & is & & is & th & 6 \\
\hline Neogi, 2009 & & & is & is & is & & & th & & is & th & 7 \\
\hline Lee, 2009 & is & & is & & & & is & is & & is & & 5 \\
\hline Liang, 2009 & is & is & is & is & is & & 动 & 动 & & 动 & 动 & 9 \\
\hline Chen, 2008 & is & कर & is & के & is & & 访 & 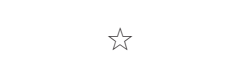 & & 动 & 虾 & 9 \\
\hline Beaussier, 2008 & is & 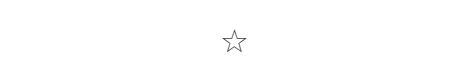 & is & is & 证 & 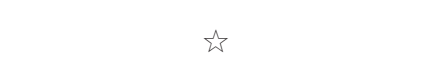 & & 虾 & & is & & 8 \\
\hline Debette, 2008 & 动 & & is & & & 弥 & 动 & 动 & & & & 5 \\
\hline Rundek, 2007 & 动 & is & is & is & 动 & & 动 & 动 & & is & 动 & 9 \\
\hline Shintani, 2007 & 动 & is & 动 & & is & & & is & & is & & 6 \\
\hline Empana, 2007 & 动 & & 弥 & is & is & is & 动 & 动 & & is & is & 9 \\
\hline Nakhai-pour, 2007 & 动 & & 动 & & & & & 弥 & 动 & is & & 5 \\
\hline Ishizaka, 2005 & is & & is & & is & & & is & & is & th & 6 \\
\hline Hintsanen, 2005 & is & th & is & & is & & is & th & & is & & 7 \\
\hline Baguet, 2005 & is & & is & & is & & & is & & is & & 5 \\
\hline Kawamoto, 2005 & is & & is & is & & & & is & & is & & 5 \\
\hline Czernichow, 2005 & is & & 虾 & 动 & $i s$ & & & 动 & & 弥 & 动 & 7 \\
\hline Lu, 2004 & is & 动 & is & & $i s$ & 动 & 动 & 动 & & 弥 & & 8 \\
\hline Tiemeier, 2004 & 虾 & & 动 & 动 & & & 动 & & & 动 & & 5 \\
\hline Kawamoto, 2001 & 动 & 动 & is & 动 & 放 & & 动 & 动 & & 动 & 动 & 9 \\
\hline Su, 2001 & 动 & is & is & is & is & & & is & & is & 放 & 8 \\
\hline
\end{tabular}


Table S2 The quality evaluation of cohort studies by the Newcastle Ottawa scale (NOS)

\begin{tabular}{|c|c|c|c|c|c|c|c|c|c|c|}
\hline \multirow[b]{2}{*}{ Study } & \multicolumn{4}{|c|}{ Selection } & \multicolumn{2}{|c|}{ Comparability } & \multicolumn{3}{|c|}{ Outcome } & \multirow{2}{*}{$\begin{array}{l}\text { Total } \\
\text { score }\end{array}$} \\
\hline & $\begin{array}{l}\text { Representativeness of the } \\
\text { exposed cohort }\end{array}$ & $\begin{array}{l}\text { Selection of the non- } \\
\text { exposed cohort }\end{array}$ & $\begin{array}{l}\text { Ascertainment of } \\
\text { exposure }\end{array}$ & $\begin{array}{l}\text { Demonstration that outcome of interest } \\
\text { was not present at start of study }\end{array}$ & $\begin{array}{l}\text { According the most important } \\
\text { factor to choose control }\end{array}$ & $\begin{array}{l}\text { According the other important } \\
\text { factor to choose control }\end{array}$ & $\begin{array}{l}\text { Assessment of } \\
\text { outcome }\end{array}$ & $\begin{array}{l}\text { Follow-up long enough } \\
\text { for outcomes to occur }\end{array}$ & $\begin{array}{l}\text { Adequacy of follow } \\
\text { up of cohorts }\end{array}$ & \\
\hline Park, 2017 & is & is & is & & is & 论 & is & & is & 7 \\
\hline Peterson, 2016 & & is & is & 放 & 弥 & 放 & is & & 放 & 7 \\
\hline Wang, 2016 & & & 动 & & 动 & & 虾 & & is & 4 \\
\hline Ramadan, 2016 & & 虾 & is & & 虾 & & is & is & & 5 \\
\hline Christoph, 2015 & is & 弥 & 放 & & is & & is & & 虾 & 6 \\
\hline Goldberg, 2014 & & is & is & & & is & is & & & 4 \\
\hline Gunnarsson, 2014 & is & 虾 & is & 弥 & 虾 & 弥 & it & & & 7 \\
\hline Kim, 2014 & & 虾 & is & & 虾 & is & & & & 4 \\
\hline Jung, 2014 & is & is & is & & is & & 放 & is & 的 & 7 \\
\hline Patel, 2013 & is & 弥 & is & & & & is & is & & 5 \\
\hline Hui, 2012 & is & is & th & & 虾 & & is & & 弥 & 6 \\
\hline Huang, 2012 & 放 & is & & & is & & is & is & & 5 \\
\hline Kesse-Guyot, 2010 & & 虾 & it & 论 & & 论 & 弥 & & & 5 \\
\hline Rice, 2009 & it & & & & 放 & 动 & is & & & 4 \\
\hline Bots, 2009 & is & 放 & it & & & & is & 放 & is & 6 \\
\hline Yamagami, 2008 & is & & is & & is & & is & & is & 5 \\
\hline Lee, 2008 & & is & is & & is & 放 & & & & 4 \\
\hline Thoenes, 2007 & & 弥 & is & & is & is & is & & is & 6 \\
\hline Mita, 2007 & is & & is & & 虾 & is & is & & is & 6 \\
\hline Haas, 2005 & & is & is & 虾 & 论 & 访 & is & & & 6 \\
\hline Hanefeld, 2004 & is & is & is & & is & 访 & is & is & is & 8 \\
\hline Zureik, 2004 & is & 虾 & it & & is & 放 & is & is & & 7 \\
\hline Lovett, 2003 & is & & is & & is & is & is & & is & 6 \\
\hline Wikstrand, 2003 & & is & is & & is & & is & is & is & 6 \\
\hline Hosomi, 2001 & 放 & 放 & is & & 动 & is & 岤 & 放 & 虾 & 8 \\
\hline
\end{tabular}




\begin{tabular}{|c|c|c|c|c|}
\hline Study & Sample types & $\begin{array}{l}\text { Stymptomatic } \\
\text { staums (TISStroke) }\end{array}$ & Comorbiditities & Drugs \\
\hline Woo, 2017 & Community population & None & 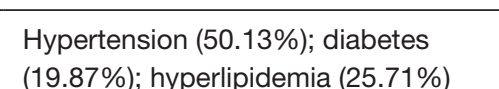 & None \\
\hline Zhang, 2016 & Community population & None & 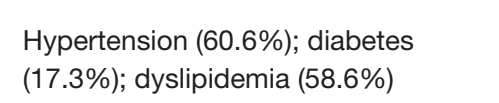 & 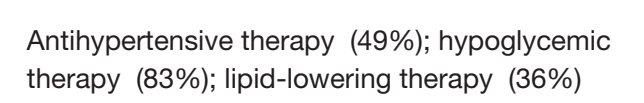 \\
\hline Idei, 2014 & $\begin{array}{l}\text { Juntrendo Toyye Koto Geriaticic } \\
\text { Metical Center }\end{array}$ & None & 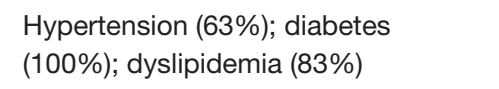 & 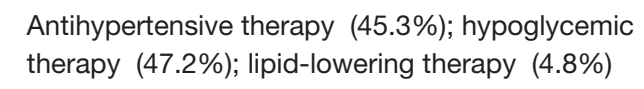 \\
\hline Hong, 2013 & Community population & None & $\begin{array}{l}\text { Hypertension (41.61\%); diabetes } \\
(9.6 \%)\end{array}$ & 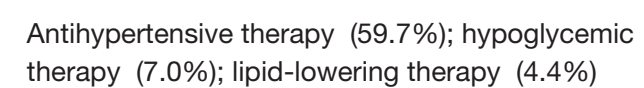 \\
\hline Beaussier, 2008 & $\begin{array}{l}\text { George Pompidido Hospital, and } \\
\text { the nueurology department of } \\
\text { Sainte-Anne Hospital }\end{array}$ & None & Hypertension (71.74\%) & Antitypertensive therapy (61.96\%) \\
\hline Empana, 2007 & Community population & None & Metabolic syndrome (12.1\%) & 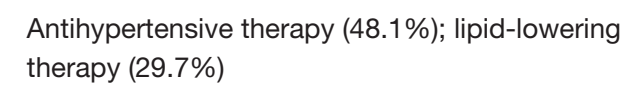 \\
\hline Czernichow, 2005 & Hotel- Dieu Hospital & None & Metabolic syndrome (8.7\%) & 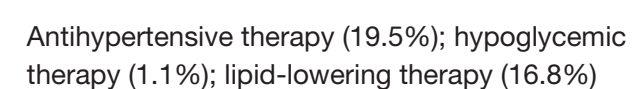 \\
\hline Su, 2001 & Community population & None & 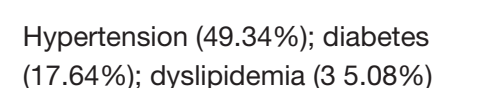 & NA \\
\hline O'Fynn, 2017 & Primary care centre & None & Hypertension (29\%); diabetes (9\%) & 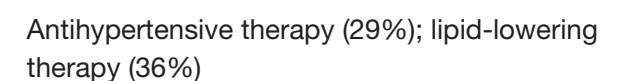 \\
\hline Rubinat, 2016 & $\begin{array}{l}\text { Hospital Universtatari Amaude } \\
\text { Vilanova }\end{array}$ & None & 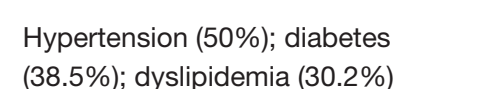 & NA \\
\hline Casanuovo, 2012 & Community population & None & $\begin{array}{l}\text { Hypertension (100\%); ;iabetes } \\
\text { (9.5\%); }\end{array}$ & 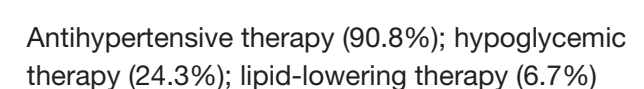 \\
\hline Yuan, 2014 & Angel of Diabetics Organisation & Stroke (2.8\%) & $\begin{array}{l}\text { Hypertension (5.6.6\%); diabotes } \\
\text { (100\%); }\end{array}$ & $\mathrm{NA}$ \\
\hline Irie, 2014 & Osaca Police Hospital & None & $\begin{array}{l}\text { Hypertension }(80 \%) \text {; diabetes } \\
\text { (1000\%): }\end{array}$ & 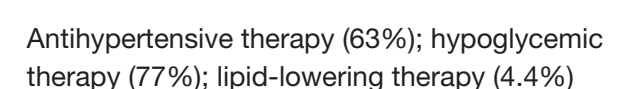 \\
\hline Sato, 2013 & Nippon Medical School Hospital & None & Diabetes (100\%) & 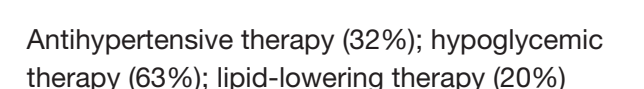 \\
\hline Johnson, 2010 & Community population & None & NA & 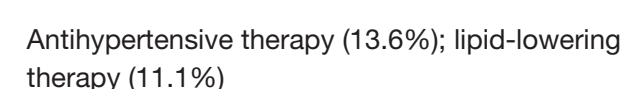 \\
\hline Leng, 2013 & Community population & None & $\begin{array}{l}\text { Hypertension (47.8\%); diabetes } \\
\text { (21.7. } 20 \text {; metabolic syndrome } \\
(62.1 \%)\end{array}$ & NA \\
\hline Chen, 2008 & Community population & None & 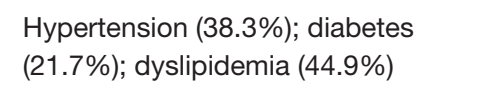 & NA \\
\hline Rundek, 2007 & Community population & None & NA & 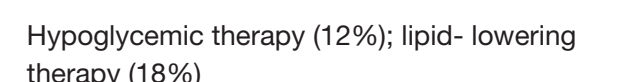 \\
\hline Ishizaka, 2005 & Missui Memorial Hospital & None & NA & NA \\
\hline Yang, 2015 & Community population & None & 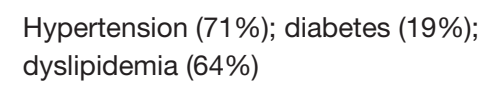 & NA \\
\hline Liang, 2009 & Fuwai Hospital & None & Hypertension (29.8\%); angina (3.4\%) & NA \\
\hline Li, 2015 & Community population & None & 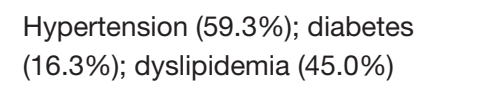 & 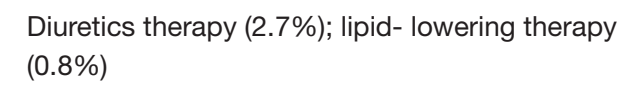 \\
\hline L, 2014 & Bejing An Znen Hospital & None & Hyperuricemia (24.9\%) & $\mathrm{NA}$ \\
\hline Neogi, 2009 & Community population & None & 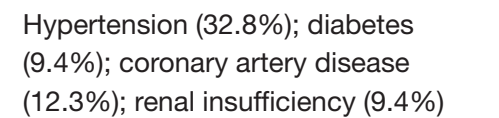 & NA \\
\hline Yang, 2014 & Community population & None & 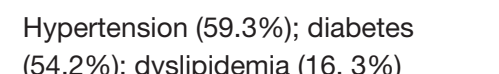 & NA \\
\hline Alsulaimani, 2013 & Community population & None & Hypertension (71\%); diabetes (20\%) & NA \\
\hline Kawamoto, 2001 & Community population & oke (40\%) & NA & NA \\
\hline Cheng, 2016 & Community population & None & 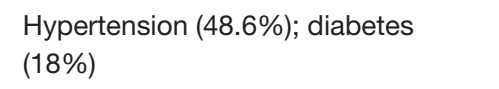 & NA \\
\hline $\begin{array}{l}\text { Lu, } 2004 \\
\text { Shintani, } 2007\end{array}$ & $\begin{array}{l}\text { Suburban general population } \\
\text { Community population }\end{array}$ & $\begin{array}{l}\text { None } \\
\text { None }\end{array}$ & 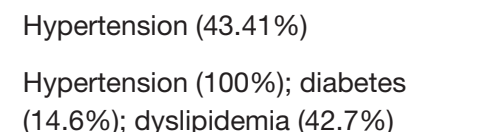 & $\begin{array}{l}\text { Antityperenensive therapy }(17.61 \%) \\
\text { Anthyperensive therapy }(39 \%)\end{array}$ \\
\hline Lovett, 2003 & European Carotid Surgery Trial & None & Hypertension (100\%) & 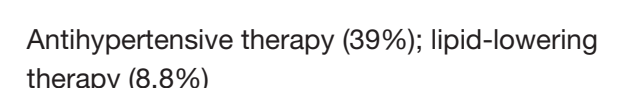 \\
\hline Huang, 2012 & Fuwa Hospital & None & NA & None \\
\hline Gardener, 2009 & Community population & None & 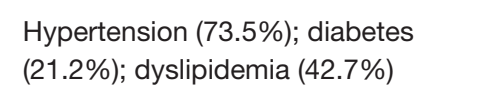 & NA \\
\hline Jung, 2014 & Ansan Hospital & Stroke (1.9\%) & 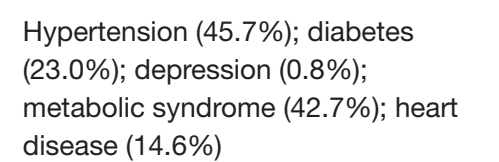 & 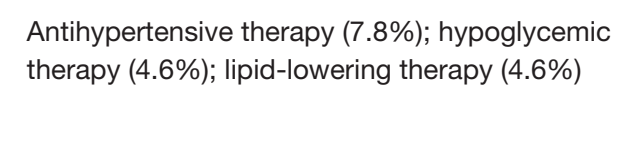 \\
\hline Oikonen, 2012 & NA & None & NA & 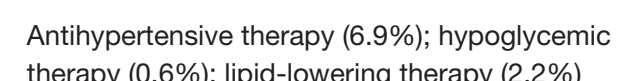 \\
\hline Zhang, 2012 & Samsung Medical Center & None & 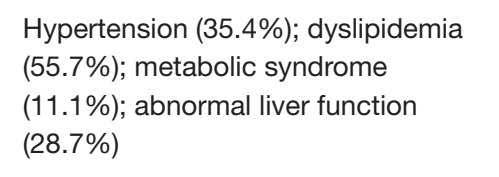 & Lipid-lowering therapy (1.4\%) \\
\hline Kawamoto, 2005 & Community population & Stroke (36.9\%) & $\begin{array}{l}\text { Hypertension (68.2\%); dyslipidemia } \\
(54.5 \%)\end{array}$ & 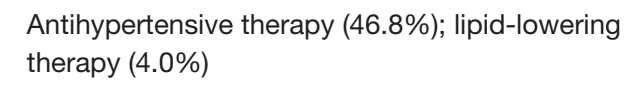 \\
\hline Nakhai-Pour, 2007 & Community population & None & $\begin{array}{l}\text { Hypertension (45\%); diabetes } \\
\text { (10.6\%\%) ;ardiovascular disease } \\
(14.1 \%)\end{array}$ & NA \\
\hline Fox, 2014 & Community population & None & None & None \\
\hline Gunnarsson, 2014 & Community population & None & NA & 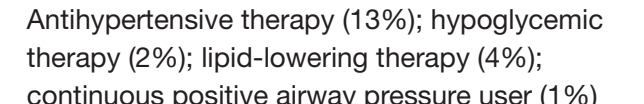 \\
\hline Kim, 2014 & Community population & None & Snoreres (73.6\%) & Antihypertensive therapy (14.9\%) \\
\hline Lee, 2008 & Community population & None & $\begin{array}{l}\text { Hypertension (27.3\%); dysipipidemia } \\
(609 \%)\end{array}$ & NA \\
\hline Baguet, 2005 & Grenoble University Hospital & None & Hypertension (40\%) & 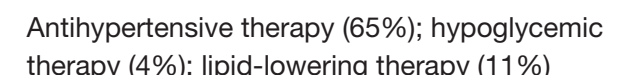 \\
\hline Haas, 2005 & Community population & None & Diabetes $(0.9 \%)$ & NA \\
\hline Rice, 2009 & & & Diabetes (5.4\%) & $\begin{array}{l}\text { Anthyyerentensive or lipid-lowerening therapy } \\
(22.3 \%) \text { antidepressants }(8.8 \%)\end{array}$ \\
\hline Tiemeier, 2004 & Community population & Stroke (3.0\%) & 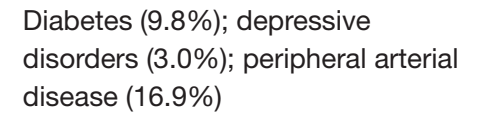 & Antidepressants (2.6\%\%) \\
\hline Peterson, 2016 & Massachusetts General Hospital & None & NA & 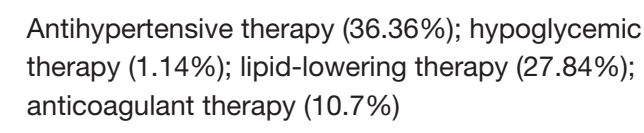 \\
\hline Thurston, 2014 & Community population & None & NA & 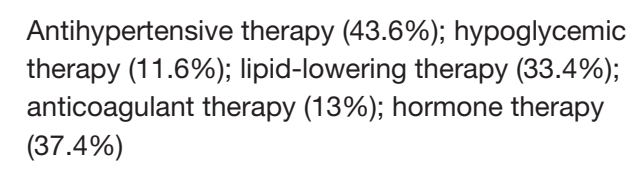 \\
\hline Hintsanen, 2005 & Social Insurance Institution & None & NA & NA \\
\hline Wang, 2016 & Community population & troke (5.8\%) & 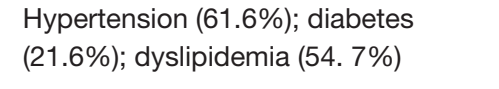 & \\
\hline Painschab, 2013 & Community population & None & 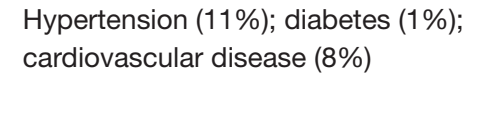 & 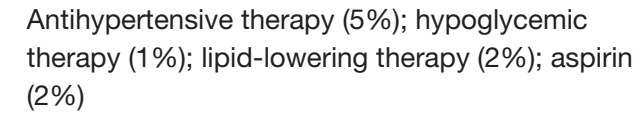 \\
\hline Park, 2017 & Community population & None & None & None \\
\hline Goldberg, 2014 & $\begin{array}{l}\text { Community popoulation } \\
\text { Community pooplation }\end{array}$ & $\begin{array}{l}\text { troke }(12 \%) \\
\text { None }\end{array}$ & 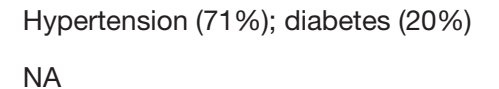 & Lipid-10 \\
\hline Sands, 2012 & NA & None & Diabetes (6.5\%); depression (15.8\%) & None \\
\hline Kesse-Guyot, 2010 & Community population & None & NA & $\begin{array}{l}\text { Antithypertensive therapy }(19.3 \%) \text {; yypoglycemic } \\
\text { theryn }\end{array}$ \\
\hline Kozakova, 2010 & Healthy subjects & None & None & None \\
\hline & Community population & $\mathrm{NA}$ & 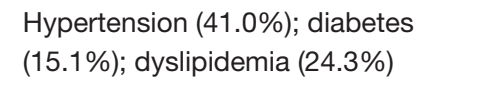 & NA \\
\hline Debette, 2008 & Community population & NA & $\begin{array}{l}\text { Hypertension (5.9.5\%), diabetes } \\
\text { (1.0.0\%) }\end{array}$ & NA \\
\hline Hui, 2012 & Community population & NA & $\begin{array}{l}\text { Obstructive sleep apnea syndrome } \\
\left(1000^{\circ}\right)\end{array}$ & Continuous positive airway pressure user (56\%) \\
\hline Thoenes, 2007 & NA & None & Metabolic syndrome $(100 \%)$ & Niacin (66.7\%) \\
\hline Zureik, 2004 & Community population & None & $\begin{array}{l}\text { Hypertension (19.8\%); diabetes } \\
(3.3 \%)\end{array}$ & $\begin{array}{l}\text { Antihypertensiviv therapy (11.2\%); vitamins } \\
\text { supolementations }\end{array}$ \\
\hline Ramadan, 2016 & NA & Stroke (3.0\%) & 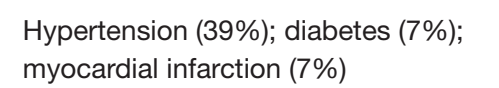 & 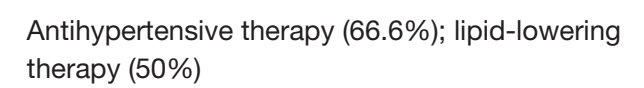 \\
\hline Wikstrand, 2003 & NA & None & Hypercholesterolemia (100\%) & $\begin{array}{l}\text { B-blockerstherapy (50\%); ipid- lowering therapy } \\
\text { (100\%) }\end{array}$ \\
\hline Hosomi, 2001 & Kagawa Medical University and & NA & Hypertension (50\%); diabetes & Antihypertensive therapy $(49.0 \%)$; hypoglycemic \\
\hline Meuwese, 2009 & NA & Stroke (2.8\%) & 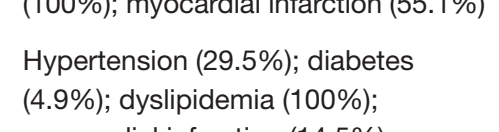 & Lipid-lowering therapy $(50.3 \%)$ \\
\hline Bots, 2009 & Caritias Carney Hospital & NA & $\begin{array}{l}\text { Hypertension (19.9\%); dysipipidemia } \\
(100 \%)\end{array}$ & Lipid-lowering therapy $(71.3 \%)$ \\
\hline Vamagami, & Kobe City General Hosp & NA & 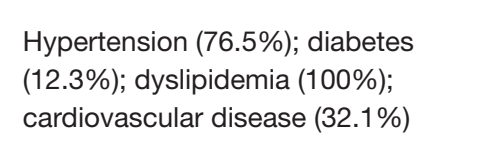 & 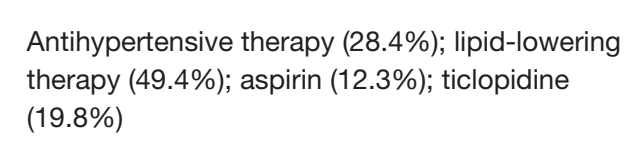 \\
\hline Christoph, 2015 & University hospital & NA & $\begin{array}{l}\text { Hypertension (79.7\%); diabetes } \\
\text { (100\%); dyslipidemia }(77.8 \%) \text { ) }\end{array}$ & 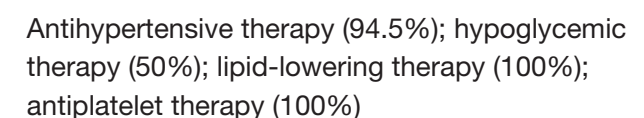 \\
\hline Patel, 2013 & 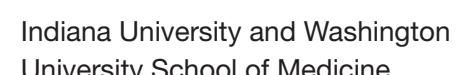 & NA & Diabetes $(100 \%)$ & 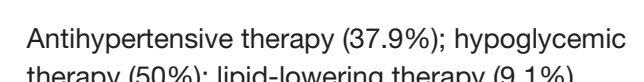 \\
\hline Mita, 2007 & 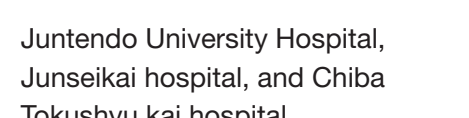 & NA & $\begin{array}{l}\text { Hypertension (32.9\%); diabetes } \\
\text { (77.5\%); dysipidemia (50\%) }\end{array}$ & 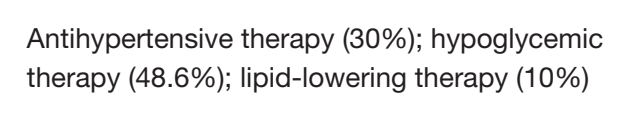 \\
\hline Hanefeld, 2004 & NA & $\mathrm{NA}$ & Diabetes (100\%) & 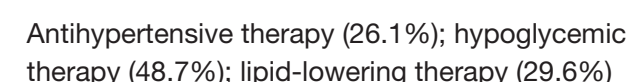 \\
\hline Blekkenhorst, 2018 & Community population & None & NA & 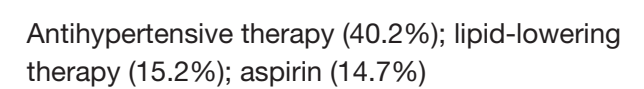 \\
\hline Bondonno, 2018 & NA & None & None & 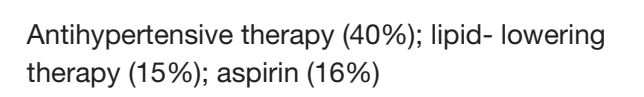 \\
\hline Johnsen, 2018 & Community population & None & (ion (55.9\%); diabetes & 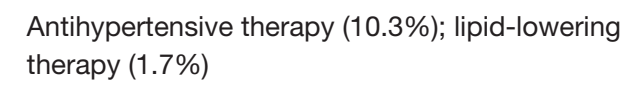 \\
\hline Kkanoush, 2017 & Community population & None & $\begin{array}{l}\text { Diabetets (18.5\%); myocardial } \\
\text { intarction (12.20) }\end{array}$ & $\begin{array}{l}\text { Antithpertensiviv therapy (25.5\%); lipid-lowering } \\
\text { therapa (11.40) }\end{array}$ \\
\hline
\end{tabular}




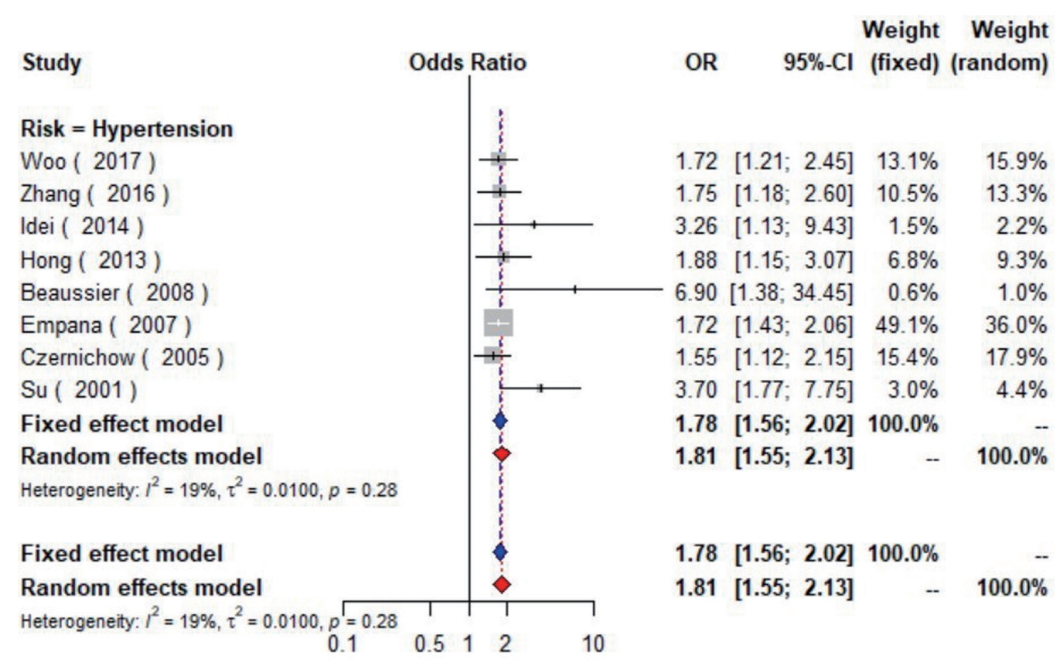

Figure S1 The forest plot shows the relationship between hypertension and the presence of carotid plaque. Each comparison is presented by the name of the first author and the year of publication. The contrast has an OR of 1.81 (95\% CI: 1.55-2.13, P=0.28) in the random effects model. Values more than 1 denote an increased risk for the presence of carotid plaque with hypertension. CI indicates confidence interval; OR, odds ratio.

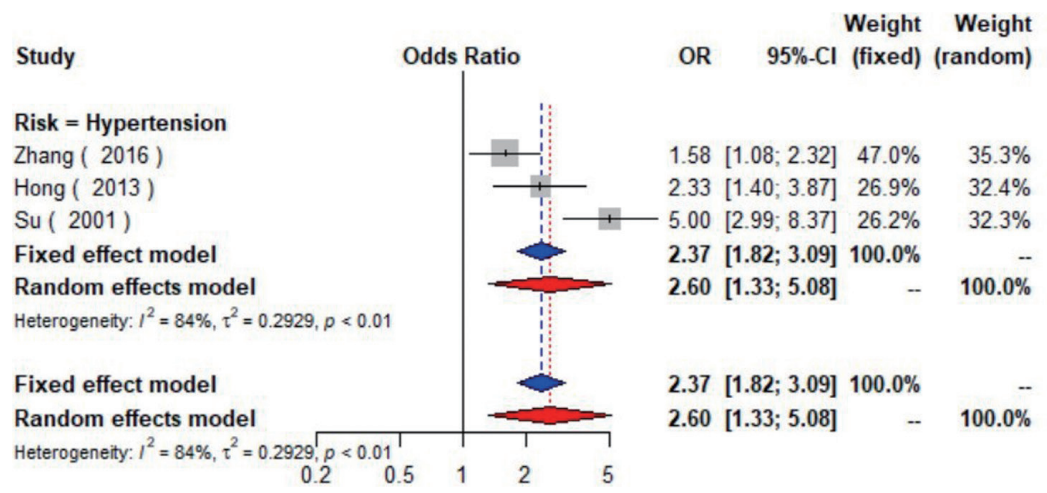

Figure S2 The forest plot shows the relationship between hypertension and the increased carotid intima media thickness. Each comparison is presented by the name of the first author and the year of publication. The contrast has an OR of 2.60 (95\% CI: 1.33-5.08, $\mathrm{P}<0.01$ ) in the random effects model. Values more than 1 denote an increased risk for the increased carotid intima media thickness with hypertension. CI, confidence interval; OR, odds ratio.

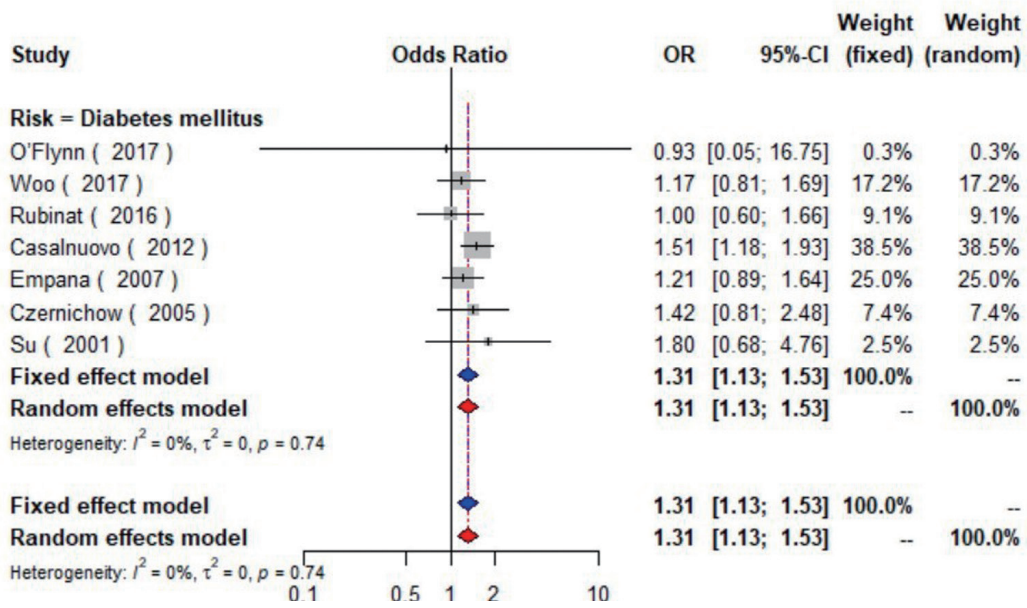

Figure S3 The forest plot shows the relationship between diabetes mellitus and the presence of carotid plaque. Each comparison is presented by the name of the first author and the year of publication. The contrast has an OR of 1.31 (95\% CI: $1.13-1.53, \mathrm{P}=0.74)$ in the random effects model. Values more than 1 denote an increased risk for the presence of carotid plaque with diabetes mellitus. CI, confidence interval; OR, odds ratio. 


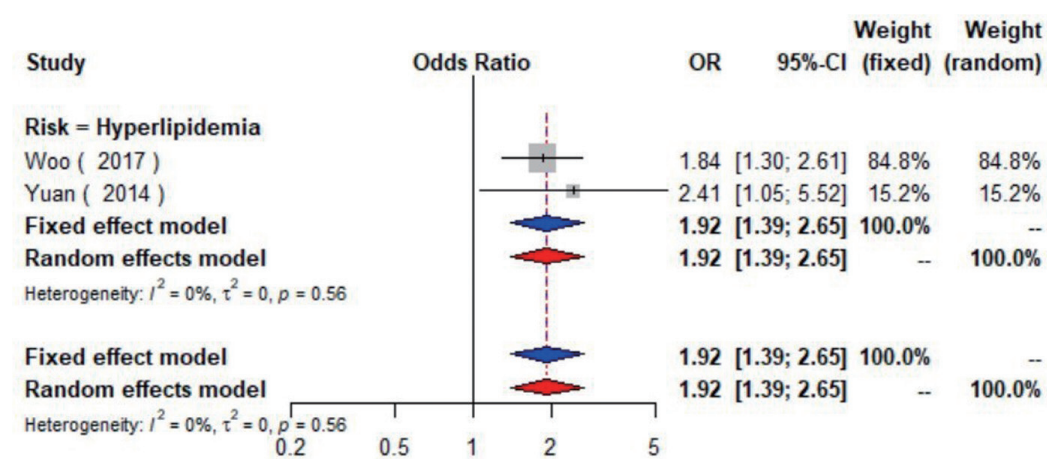

Figure S4 The forest plot shows the relationship between hyperlipidemia and the presence of carotid plaque. Each comparison is presented by the name of the first author and the year of publication. The contrast has an OR of 1.92 (95\% CI: 1.39-2.65, P=0.56) in the random effects model. Values more than 1 denote an increased risk for the presence of carotid plaque with hyperlipidemia. CI, confidence interval; OR, odds ratio.

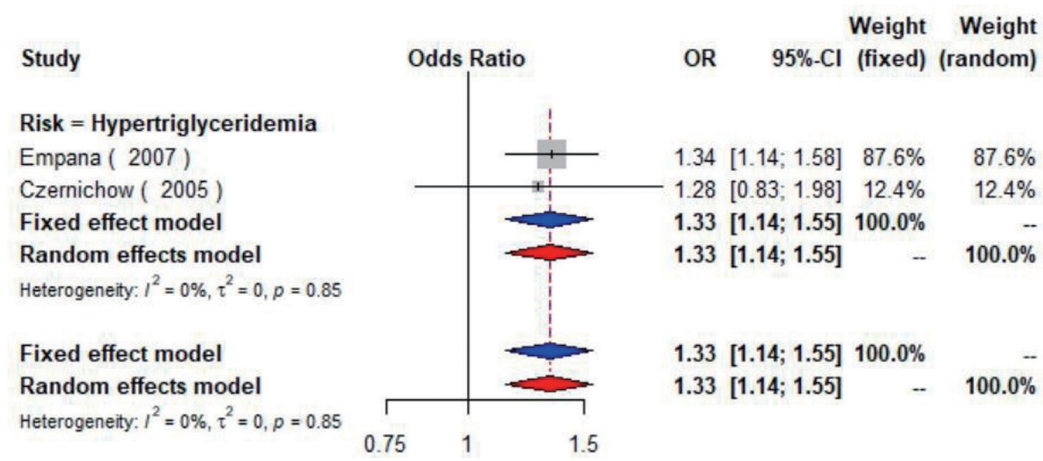

Figure S5 The forest plot shows the relationship between hypertriglyceridemia and the presence of carotid plaque. Each comparison is presented by the name of the first author and the year of publication. The contrast has an OR of 1.33 (95\% CI: 1.14-1.55, P=0.85) in the random effects model. Values more than 1 denote an increased risk for the presence of carotid plaque with hyperlipidemia. CI, confidence interval; OR, odds ratio.
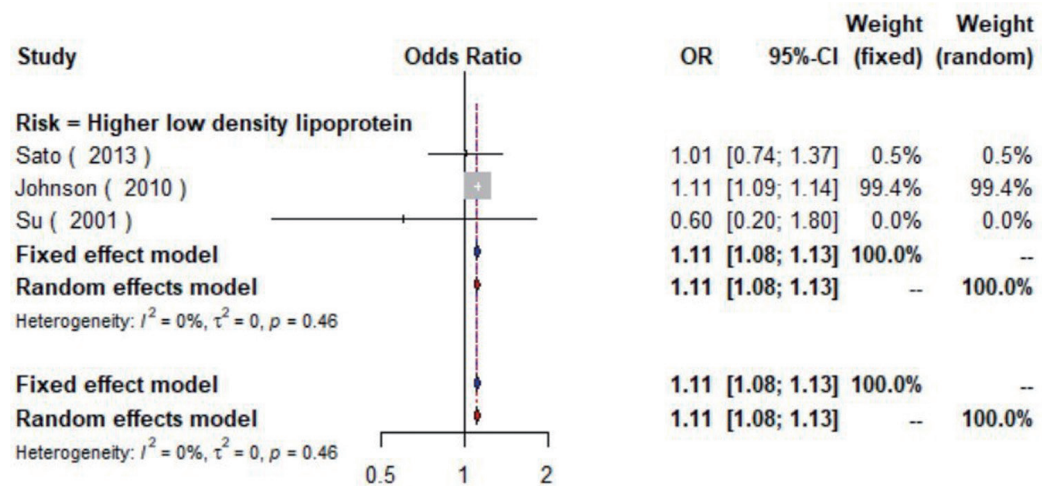

Figure S6 The forest plot shows the relationship between higher low density lipoprotein and the presence of carotid plaque. Each comparison is presented by the name of the first author and the year of publication. The contrast has an OR of 1.11 (95\% CI: 1.08-1.13, $\mathrm{P}=0.46$ ) in the random effects model. Values more than 1 denote an increased risk for the presence of carotid plaque with higher low-density lipoprotein. CI, confidence interval; OR, odds ratio. 


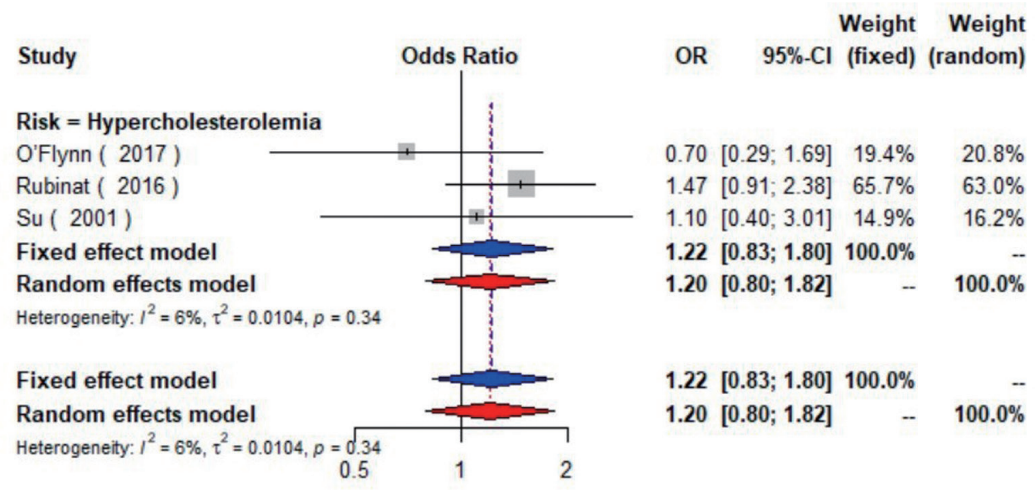

Figure S7 The forest plot shows the relationship between hypercholesterolemia and the presence of carotid plaque. Each comparison is presented by the name of the first author and the year of publication. The contrast has an OR of 1.20 (95\% CI: $0.80-1.82, \mathrm{P}=0.34)$ in the random effects model. Values across 1 means there are no relationship between hypercholesterolemia and the presence of carotid plaque. CI, confidence interval; OR, odds ratio.

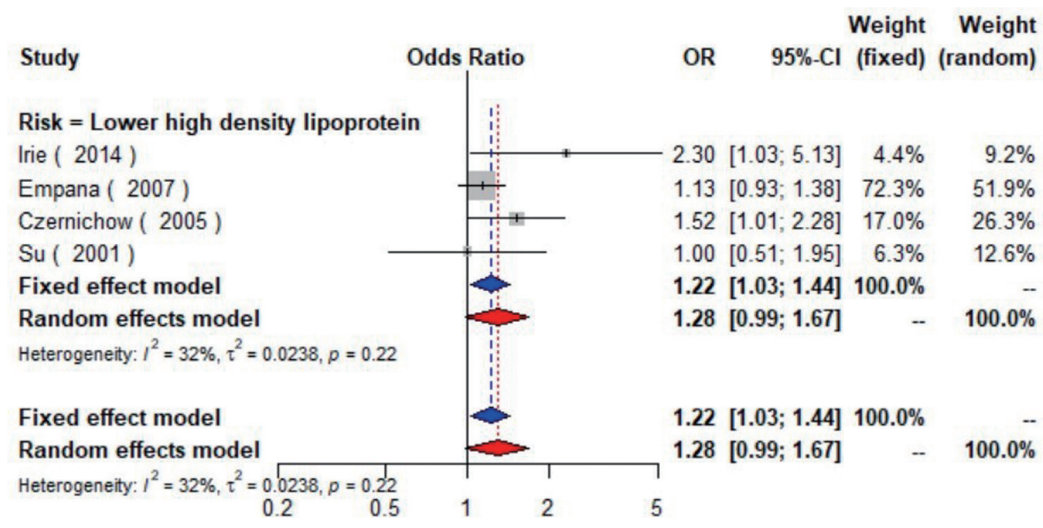

Figure S8 The forest plot shows the relationship between lower high density lipoprotein and the presence of carotid plaque. Each comparison is presented by the name of the first author and the year of publication. The contrast has an OR of 1.28 (95\% CI: 0.99-1.67, $\mathrm{P}=0.22)$ in the random effects model. Values across 1 means there are no relationship between lower high-density lipoprotein and the presence of carotid plaque. CI, confidence interval; OR, odds ratio.

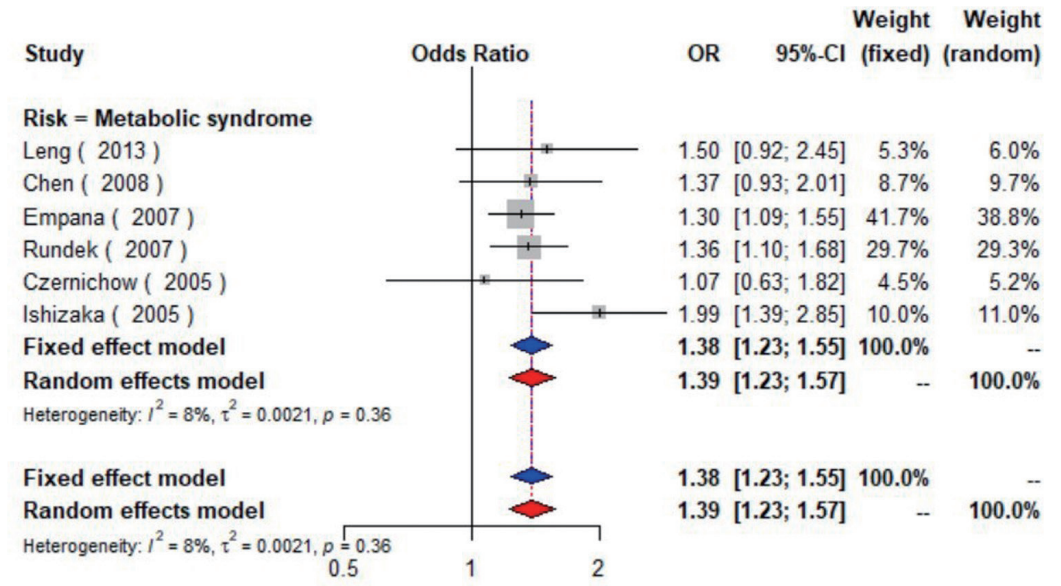

Figure S9 The forest plot shows the relationship between metabolic syndrome and the presence of carotid plaque. Each comparison is presented by the name of the first author and the year of publication. The contrast has an OR of 1.39 (95\% CI: 1.23-1.57, P=0.36) in the random effects model. Values more than 1 denote an increased risk for the presence of carotid plaque with metabolic syndrome. CI, confidence interval; OR, odds ratio. 


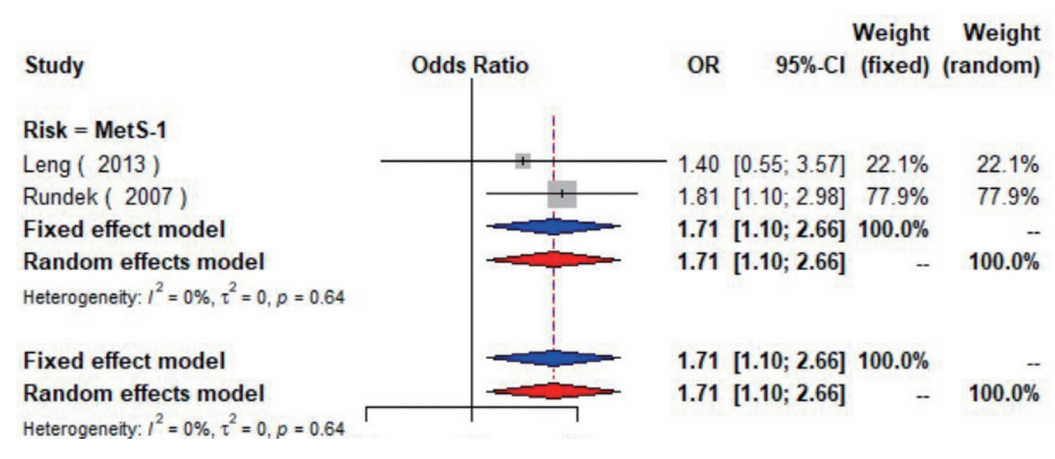

Figure S10 The forest plot shows the relationship between one component of metabolic syndrome and the presence of carotid plaque. Each comparison is presented by the name of the first author and the year of publication. The contrast has an OR of 1.71 (95\% CI: 1.10-2.66, $\mathrm{P}=0.64)$ in the random effects model. Values more than 1 denote an increased risk for the presence of carotid plaque with one component of metabolic syndrome. CI, confidence interval; OR, odds ratio; MetS-1, one component of metabolic syndrome.

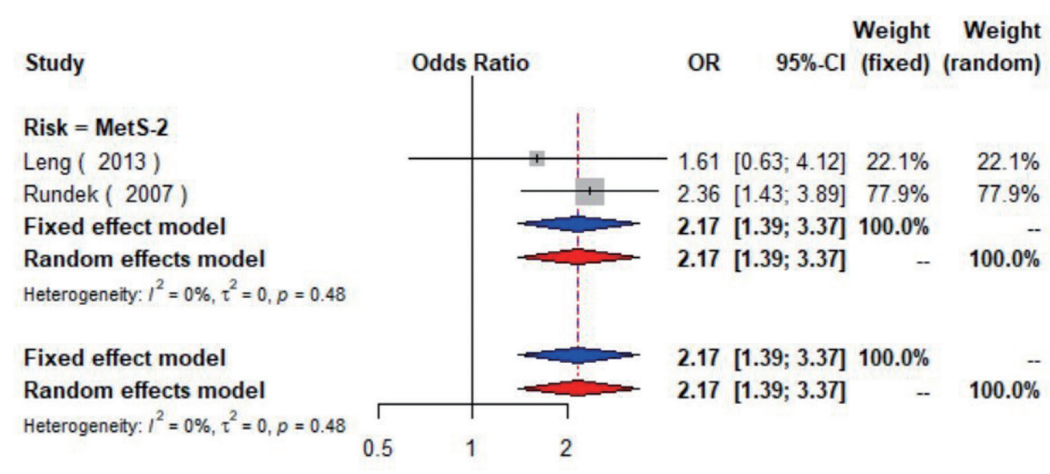

Figure S11 The forest plot shows the relationship between two components of metabolic syndrome and the presence of carotid plaque. Each comparison is presented by the name of the first author and the year of publication. The contrast has an OR of 2.17 (95\% CI: 1.39-3.37, $\mathrm{P}=0.48$ ) in the random effects model. Values more than 1 denote an increased risk for the presence of carotid plaque with two components of metabolic syndrome. CI, confidence interval; OR, odds ratio; MetS-2, two components of metabolic syndrome.

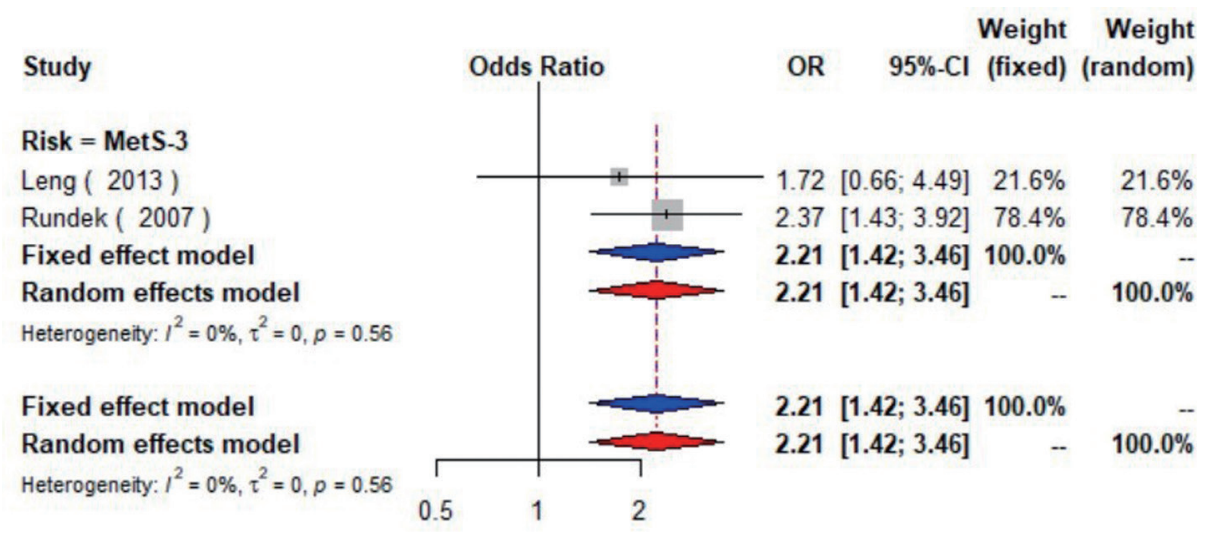

Figure S12 The forest plot shows the relationship between three components of metabolic syndrome and the presence of carotid plaque. Each comparison is presented by the name of the first author and the year of publication. The contrast has an OR of 2.21 (95\% CI: 1.42-3.46, $\mathrm{P}=0.56$ ) in the random effects model. Values more than 1 denote an increased risk for the presence of carotid plaque with three components of metabolic syndrome. CI, confidence interval; OR, odds ratio; MetS-3, three components of metabolic syndrome. 


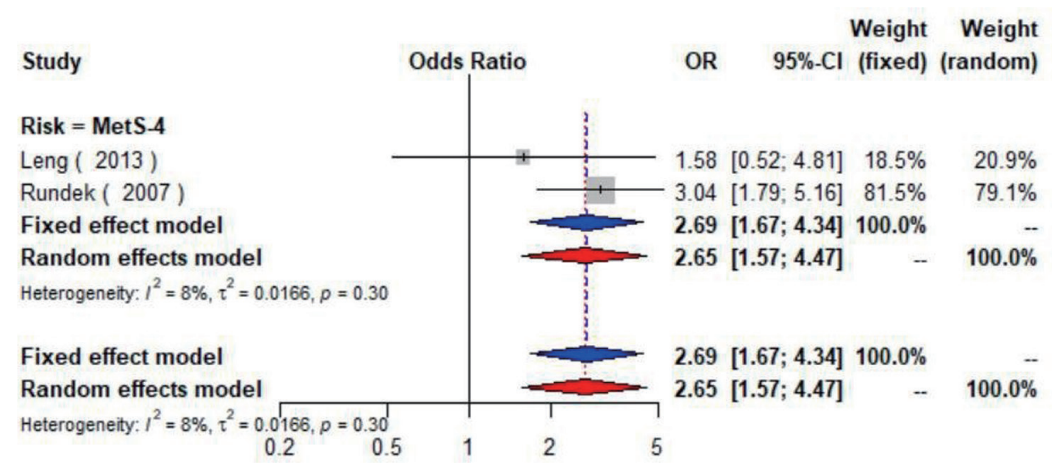

Figure S13 The forest plot shows the relationship between four components of metabolic syndrome and the presence of carotid plaque. Each comparison is presented by the name of the first author and the year of publication. The contrast has an OR of 2.65 (95\% CI: 1.57-4.47, $\mathrm{P}=0.30)$ in the random effects model. Values more than 1 denote an increased risk for the presence of carotid plaque with four components of metabolic syndrome. CI, confidence interval; OR, odds ratio; MetS-4, four components of metabolic syndrome.

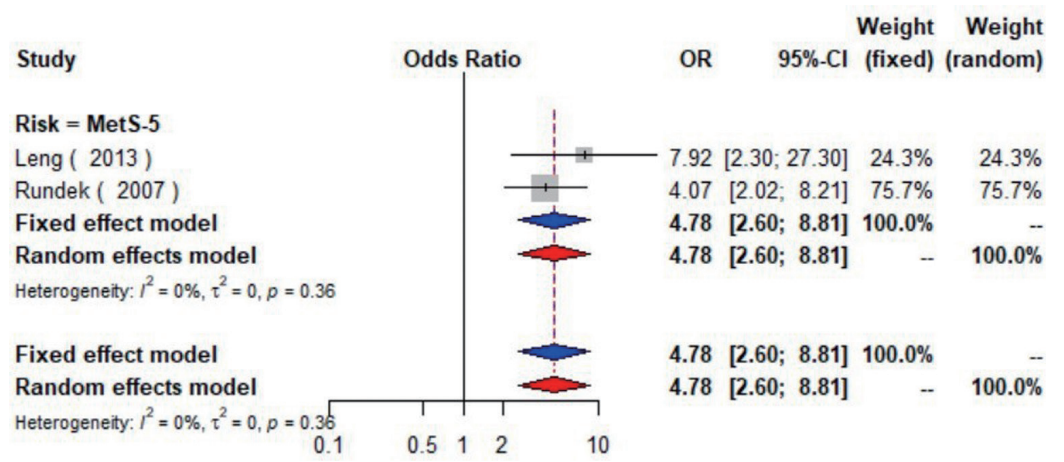

Figure S14 The forest plot shows the relationship between five components of metabolic syndrome and the presence of carotid plaque. Each comparison is presented by the name of the first author and the year of publication. The contrast has an OR of 4.78 (95\% CI: 2.60-8.81, $\mathrm{P}=0.36$ ) in the random effects model. Values more than 1 denote an increased risk for the presence of carotid plaque with five components of metabolic syndrome. CI, confidence interval; OR, odds ratio; MetS-5, five components of metabolic syndrome.

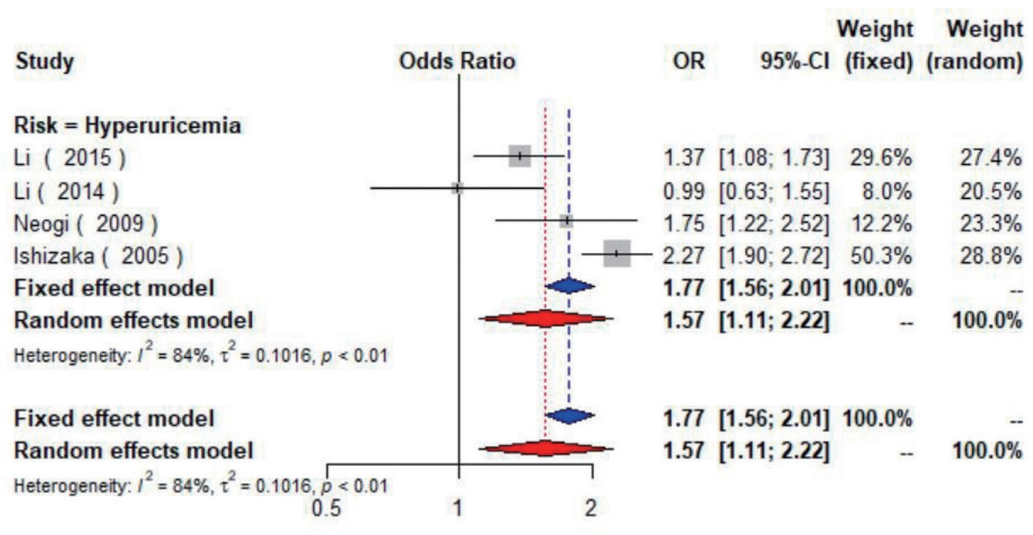

Figure S15 The forest plot shows the relationship between hyperuricemia and the presence of carotid plaque. Each comparison is presented by the name of the first author and the year of publication. The contrast has an OR of 1.57 (95\% CI: 1.11-2.22, P<0.01) in the random effects model. Values more than 1 denote an increased risk for the presence of carotid plaque with hyperuricemia. CI, confidence interval; OR, odds ratio. 


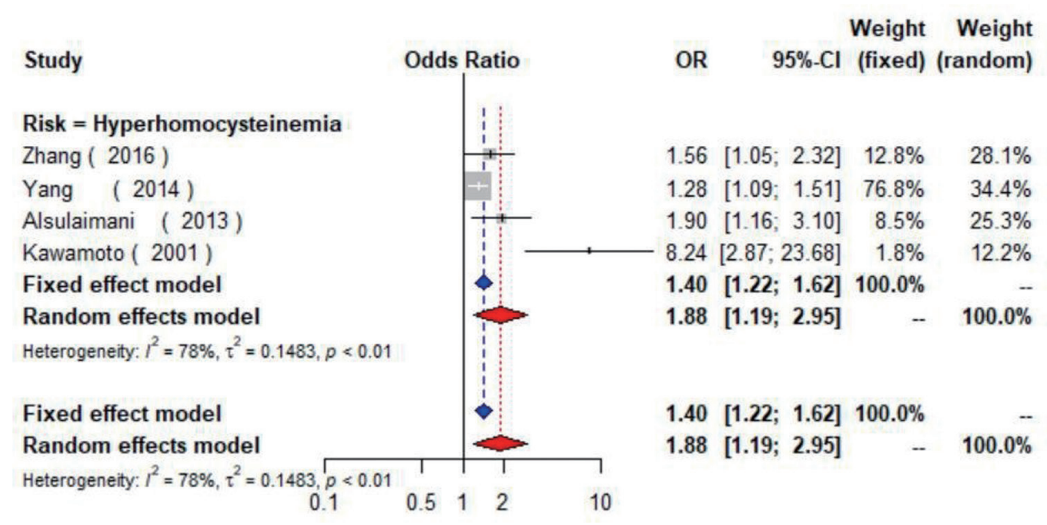

Figure S16 The forest plot shows the relationship between hyperhomocysteinemia and the presence of carotid plaque. Each comparison is presented by the name of the first author and the year of publication. The contrast has an OR of 1.88 (95\% CI: 1.19-2.95, P<0.01) in the random effects model. Values more than an increased risk for the presence of carotid plaque with hyperhomocysteinemia. CI, confidence interval; OR, odds ratio.

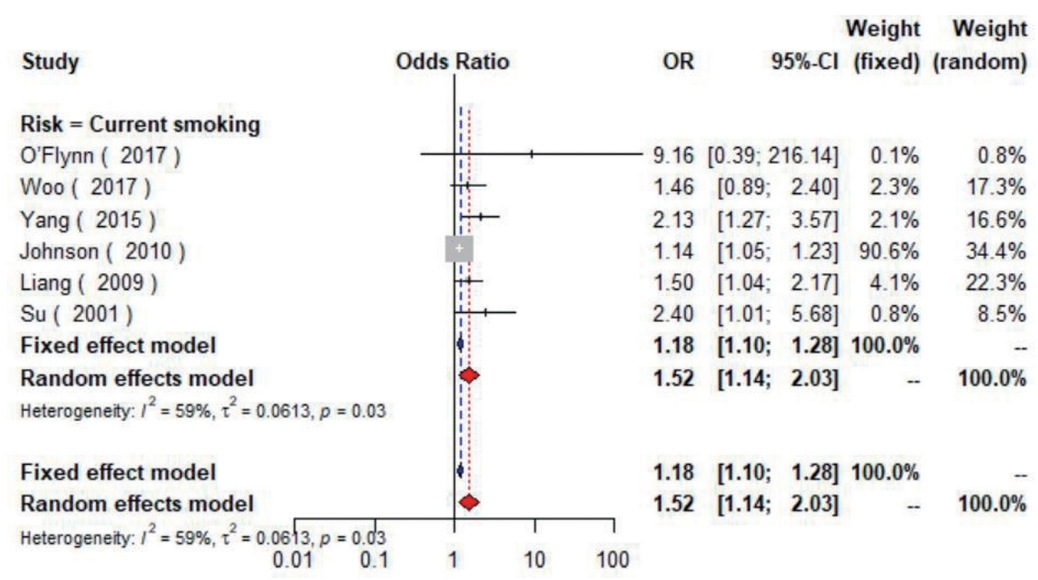

Figure S17 The forest plot shows the relationship between current smoking and the presence of carotid plaque. Each comparison is presented by the name of the first author and the year of publication. The contrast has an OR of 1.52 (95\% CI: 1.14-2.03, P=0.03) in the random effects model. Values more than an increased risk for the presence of carotid plaque with current smoking. CI, confidence interval; OR, odds ratio.

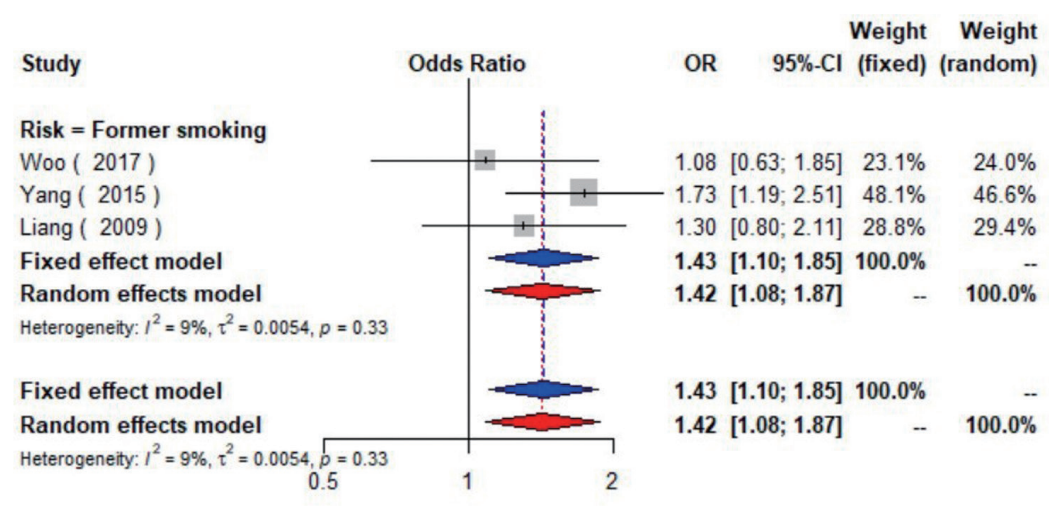

Figure S18 The forest plot shows the relationship between former smoking and the presence of carotid plaque. Each comparison is presented by the name of the first author and the year of publication. The contrast has an OR of 1.42 (95\% CI: $1.08-1.87, \mathrm{P}=0.33$ ) in the random effects model. Values more than an increased risk for the presence of carotid plaque with former smoking. CI, confidence interval; OR, odds ratio. 
Table S4 Sensitivity analysis of the meta-analysis

\begin{tabular}{|c|c|c|c|c|c|c|}
\hline Risk factor & Study omitted & OR & $\mathrm{LCl}$ & $\mathrm{LCl}$ & Heterogeneity $\left(I^{2}\right)$ & $P$ value \\
\hline \multirow[t]{9}{*}{ Hypertension (presence of plaque) } & None & 1.81 & 1.55 & 2.13 & $19 \%$ & 0.28 \\
\hline & Woo, 2017 & 1.87 & 1.53 & 2.29 & $30 \%$ & 0.20 \\
\hline & Zhang, 2016 & 1.86 & 1.53 & 2.26 & $31 \%$ & 0.19 \\
\hline & Idei, 2014 & 1.79 & 1.52 & 2.10 & $19 \%$ & 0.29 \\
\hline & Hong, 2013 & 1.83 & 1.52 & 2.22 & $30 \%$ & 0.20 \\
\hline & Beaussier, 2008 & 1.76 & 1.55 & 2.00 & $0 \%$ & 0.43 \\
\hline & Empana, 2007 & 1.92 & 1.52 & 2.41 & $29 \%$ & 0.21 \\
\hline & Czernichow, 2005 & 1.90 & 1.57 & 2.30 & $24 \%$ & 0.25 \\
\hline & Su, 2001 & 1.74 & 1.53 & 1.98 & $0 \%$ & 0.57 \\
\hline \multirow[t]{4}{*}{ Hypertension (increased CIMT) } & None & 2.60 & 1.33 & 5.08 & $84 \%$ & $<0.01$ \\
\hline & Zhang, 2016 & 3.41 & 1.61 & 7.21 & $77 \%$ & 0.04 \\
\hline & Hong, 2013 & 2.77 & 0.90 & 8.57 & $92 \%$ & $<0.01$ \\
\hline & Su, 2001 & 1.85 & 1.27 & 2.69 & $30 \%$ & 0.23 \\
\hline \multirow[t]{8}{*}{ Diabetes mellitus } & None & 1.31 & 1.13 & 1.53 & $0 \%$ & 0.74 \\
\hline & O'Flynn, 2017 & 1.32 & 1.13 & 1.53 & $0 \%$ & 0.63 \\
\hline & Woo, 2017 & 1.34 & 1.14 & 1.59 & $0 \%$ & 0.69 \\
\hline & Rubinat, 2016 & 1.35 & 1.15 & 1.59 & $0 \%$ & 0.81 \\
\hline & Casalnuovo, 2014 & 1.21 & 0.99 & 1.46 & $0 \%$ & 0.91 \\
\hline & Empana, 2007 & 1.35 & 1.13 & 1.61 & $0 \%$ & 0.68 \\
\hline & Czernichow, 2005 & 1.31 & 1.11 & 1.53 & $0 \%$ & 0.63 \\
\hline & Su, 2001 & 1.30 & 1.12 & 1.52 & $0 \%$ & 0.68 \\
\hline \multirow[t]{4}{*}{ Hypercholesterolemia } & None & 1.20 & 0.80 & 1.82 & $6 \%$ & 0.34 \\
\hline & O’Flynn, 2017 & 1.39 & 0.90 & 2.15 & $0 \%$ & 0.61 \\
\hline & Rubinat, 2016 & 0.85 & 0.44 & 1.66 & $0 \%$ & 0.51 \\
\hline & Su, 2001 & 1.12 & 0.55 & 2.25 & $52 \%$ & 0.15 \\
\hline \multirow[t]{4}{*}{ Higher low-density lipoprotein } & None & 1.11 & 1.08 & 1.13 & $0 \%$ & 0.46 \\
\hline & Sato, 2013 & 1.05 & 0.75 & 1.47 & $17 \%$ & 0.27 \\
\hline & Johnson, 2010 & 0.97 & 0.73 & 1.31 & $0 \%$ & 0.37 \\
\hline & Su, 2001 & 1.11 & 1.08 & 1.13 & $0 \%$ & 0.55 \\
\hline \multirow[t]{5}{*}{ Lower high density lipoprotein } & None & 1.28 & 0.99 & 1.67 & $32 \%$ & 0.22 \\
\hline & Irie, 2014 & 1.18 & 1.00 & 1.40 & $0 \%$ & 0.39 \\
\hline & Empana, 2007 & 1.47 & 1.01 & 2.15 & $20 \%$ & 0.29 \\
\hline & Czernichow, 2005 & 1.27 & 0.83 & 1.75 & $34 \%$ & 0.22 \\
\hline & Su, 2001 & 1.37 & 0.98 & 1.92 & $51 \%$ & 0.13 \\
\hline \multirow[t]{7}{*}{ Metabolic syndrome } & None & 1.39 & 1.23 & 1.57 & $8 \%$ & 0.36 \\
\hline & Leng, 2013 & 1.39 & 1.20 & 1.60 & $25 \%$ & 0.26 \\
\hline & Chen, 2008 & 1.40 & 1.20 & 1.63 & $26 \%$ & 0.25 \\
\hline & Empana, 2007 & 1.45 & 1.22 & 1.75 & $15 \%$ & 0.32 \\
\hline & Rundek, 2007 & 1.42 & 1.18 & 1.69 & $26 \%$ & 0.25 \\
\hline & Czernichow, 2005 & 1.41 & 1.24 & 1.60 & $12 \%$ & 0.34 \\
\hline & Ishizaka, 2005 & 1.32 & 1.17 & 1.49 & $0 \%$ & 0.91 \\
\hline \multirow[t]{5}{*}{ Hyperuricemia } & None & 1.57 & 1.11 & 2.22 & $84 \%$ & $<0.01$ \\
\hline & $\mathrm{Li}, 2015$ & 1.64 & 1.04 & 2.58 & $83 \%$ & $<0.01$ \\
\hline & $\mathrm{Li}, 2014$ & 1.77 & 1.26 & 2.5 & $82 \%$ & $<0.01$ \\
\hline & Neogi, 2009 & 1.5 & 0.95 & 2.38 & $89 \%$ & $<0.01$ \\
\hline & Ishizaka, 2005 & 1.37 & 1.05 & 1.79 & $46 \%$ & 0.16 \\
\hline \multirow[t]{5}{*}{ Hyperhomocysteinemia } & None & 1.88 & 1.19 & 2.95 & $78 \%$ & $<0.01$ \\
\hline & Zhang, 2016 & 2.24 & 1.08 & 4.67 & $85 \%$ & $<0.01$ \\
\hline & Yang, 2014 & 2.43 & 1.22 & 4.83 & $76 \%$ & 0.02 \\
\hline & Alsulaimani, 2013 & 1.97 & 1.07 & 3.61 & $84 \%$ & $<0.01$ \\
\hline & Kawamoto, 2001 & 1.42 & 1.15 & 1.75 & $28 \%$ & 0.25 \\
\hline \multirow[t]{7}{*}{ Current smoking } & None & 1.52 & 1.14 & 2.03 & $59 \%$ & 0.09 \\
\hline & O’Flynn, 2017 & 1.49 & 1.13 & 1.98 & $63 \%$ & 0.03 \\
\hline & Woo, 2017 & 1.57 & 1.10 & 2.24 & $66 \%$ & 0.02 \\
\hline & Yang, 2015 & 1.37 & 1.06 & 1.78 & $44 \%$ & 0.13 \\
\hline & Johnson, 2010 & 1.70 & 1.33 & 2.17 & 0 & 0.52 \\
\hline & Liang, 2009 & 1.59 & 1.08 & 2.33 & $63 \%$ & 0.03 \\
\hline & Su, 2001 & 1.44 & 1.09 & 1.92 & $59 \%$ & 0.05 \\
\hline \multirow[t]{4}{*}{ Former smoking } & None & 1.42 & 1.08 & 1.87 & $9 \%$ & 0.33 \\
\hline & Woo, 2017 & 1.55 & 1.16 & 2.09 & $0 \%$ & 0.36 \\
\hline & Yang, 2015 & 1.20 & 0.84 & 1.71 & $0 \%$ & 0.62 \\
\hline & Liang, 2009 & 1.43 & 0.90 & 2.24 & $50 \%$ & 0.16 \\
\hline
\end{tabular}

OR, odds ratio; LCl, lower confidence interval; UCl, upper confidence interval. 


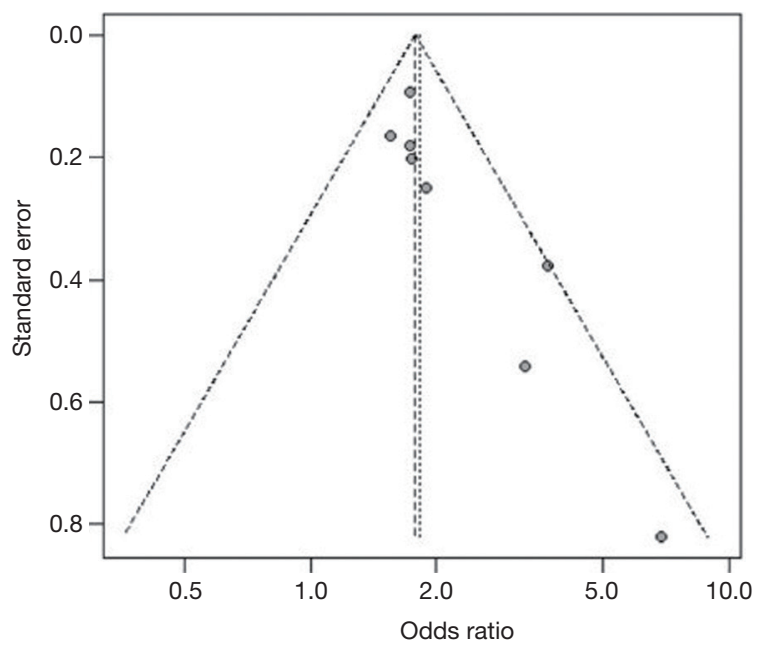

Figure S19 Funnel plot for publication bias in studies on hypertension and the presence of carotid plaque. The asymmetry of the funnel plot suggests that publication bias may exist.

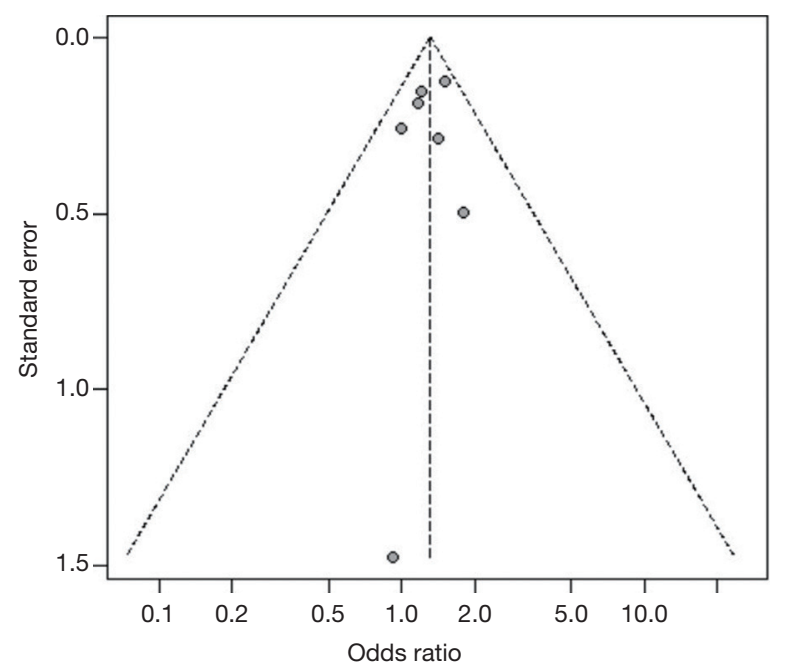

Figure S20 Funnel plot for publication bias in studies on diabetes mellitus and the presence of carotid plaque. The asymmetry of the funnel plot suggests that publication bias may exist.

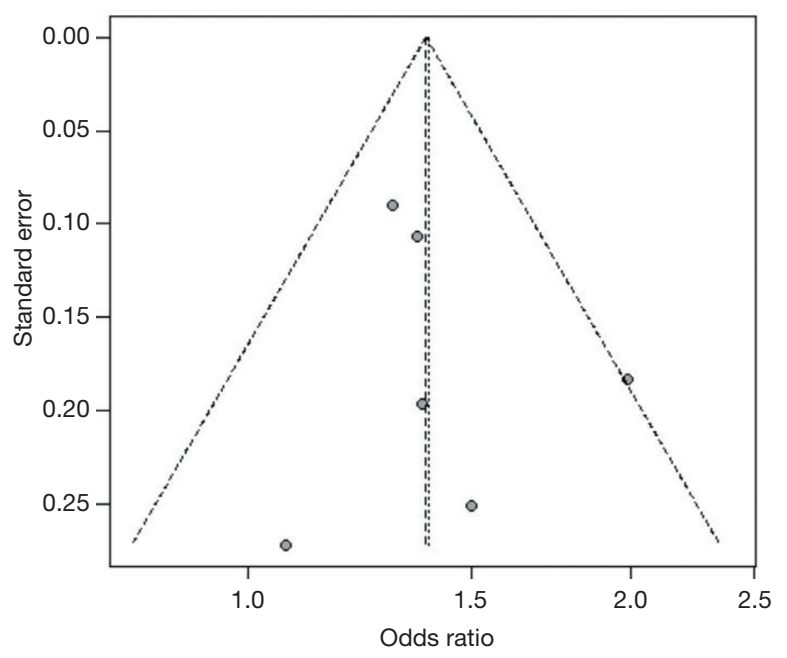

Figure S21 Funnel plot for publication bias in studies on metabolic syndrome and the presence of carotid plaque. The asymmetry of the funnel plot suggests that publication bias may exist.

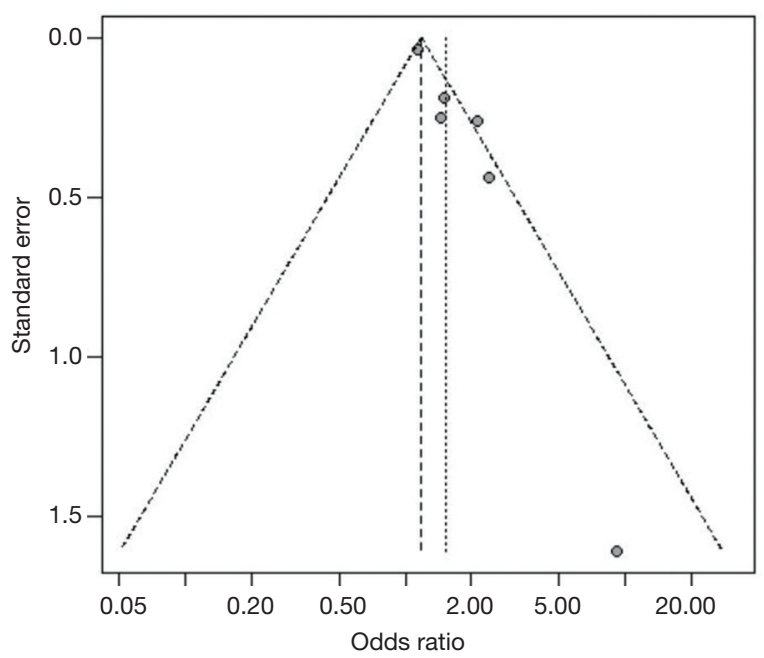

Figure S22 Funnel plot for publication bias in studies on current smoking and the presence of carotid plaque. The asymmetry of the funnel plot suggests that publication bias may exist.

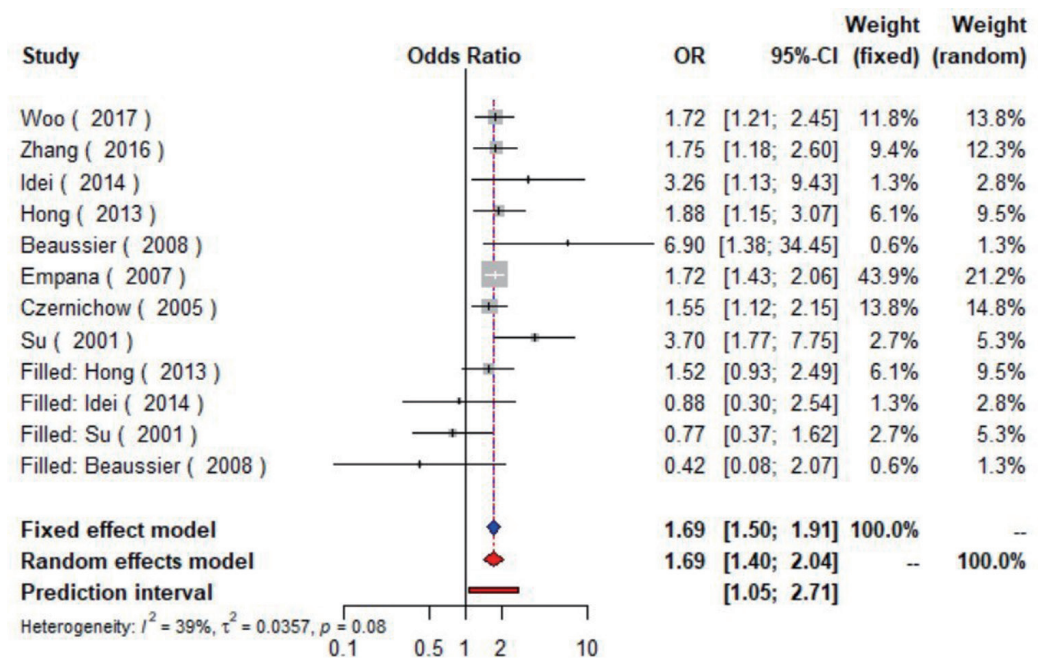

Figure S23 After using the trim and filling method, the change of the merger effect was not obvious. The results were moderate, which means hypertension is a risk factor for the presence of carotid plaque. 


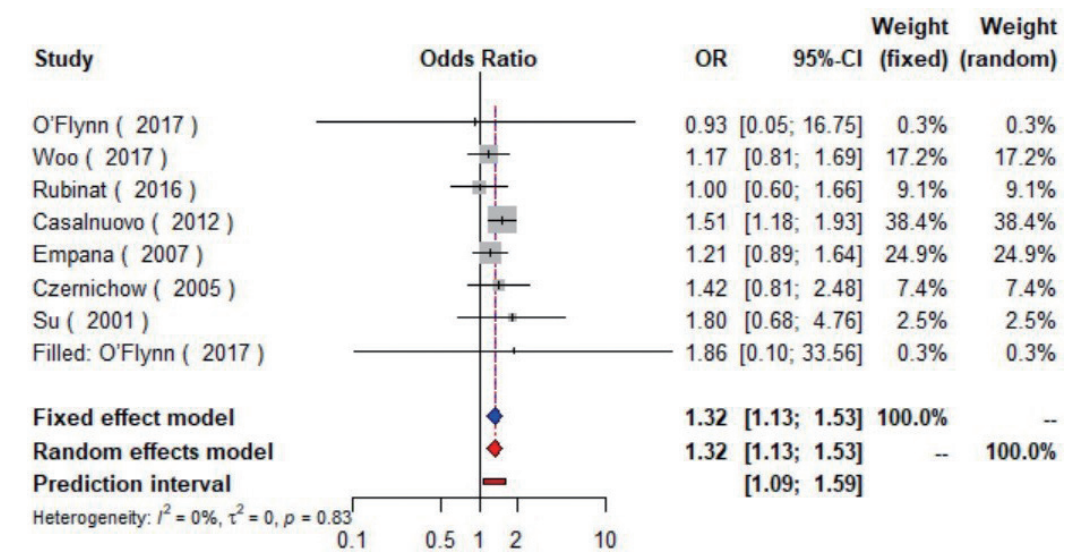

Figure S24 After using the trim and filling method, the change of the merger effect was not obvious. The results were moderate, which means diabetes mellitus is a risk factor for the presence of carotid plaque.

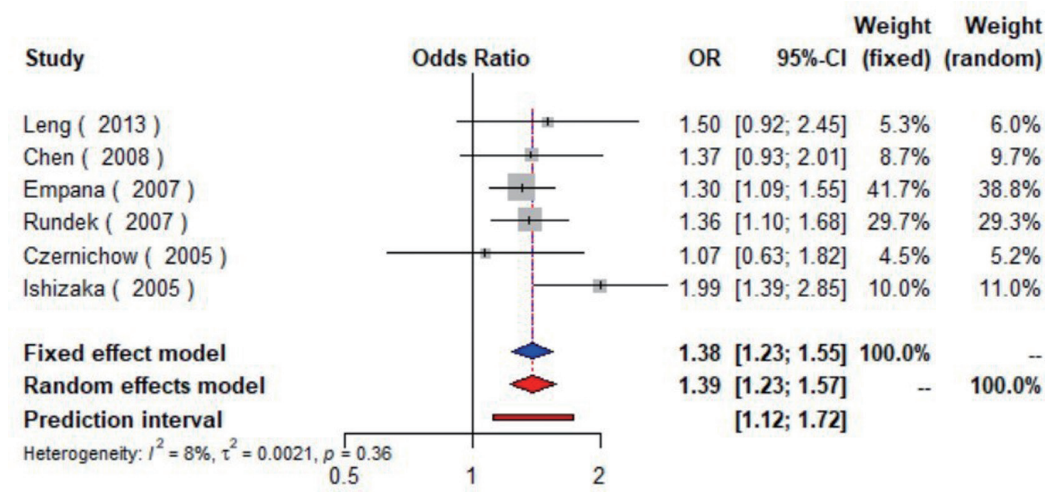

Figure S25 After using the trim and filling method, the change of the merger effect was not obvious. The results were moderate, which means metabolic syndrome is a risk factor for the presence of carotid plaque.

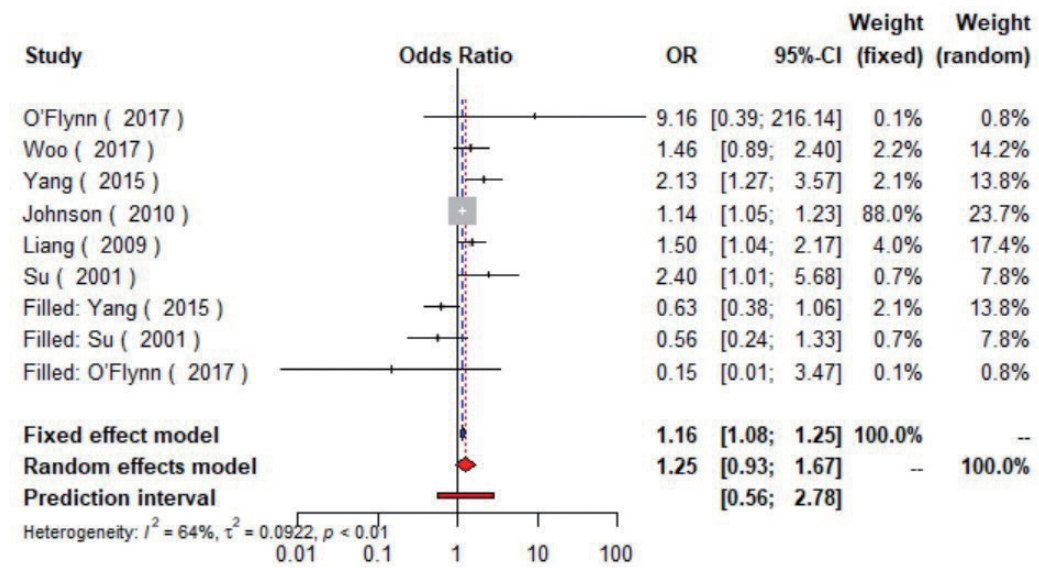

Figure S26 After using the trim and filling method, the merger effect became non-significant. The results were not moderate, which means the caution is needed in drawing conclusion. 


\begin{tabular}{|c|c|c|c|c|c|c|c|c|c|c|}
\hline Risk factors & Study & Study type & $\begin{array}{c}\text { Recruitment } \\
\text { period }\end{array}$ & $\mathrm{N}$ (total) & Age (range, mean $\pm S D$ ) & Sex (female), \% & Follow-up & Lost to follow-up & Outcome & Result \\
\hline \multicolumn{11}{|l|}{ Hypertension } \\
\hline Systolic blood pressure variability & O'Flynn, 2017 & Cross-sectional & 2010 & 50 & $59 \pm 6$ years & 51.00 & NA & NA & Plaque $^{*}$ & OR $1.90(1.10-3.20)$ \\
\hline Pulse pressure & Cheng, 2016 & Cross-sectional & 2011-2012 & 5,403 & $56.59 \pm 9.1$ years & 63.00 & NA & NA & CIMT† & OR $1.11(1.05-1.08)$ \\
\hline Diastolic blood pressure variability & Li, 2014 & Cross-sectional & 2007 & 1,222 & $65.2 \pm 8.0$ years & 54.50 & NA & NA & Plaque $^{*}$ & OR $6.07(1.31-28.10)$ \\
\hline Duration of hypertension & Lu, 2004 & Cross-sectional & 2002 & 1,198 & $43-73$ years & 64.77 & NA & NA & Plaque $^{*}$ & $\begin{array}{l}\text { OR 2.2(1.1-4.3) (woman), } \\
\text { OR 1.0 (0.4-2.4) (man) }\end{array}$ \\
\hline Systolic blood pressure variability & Shintani, 2007 & Cross-sectional & 1998 & 775 & $66.2 \pm 6.2$ years & 68.80 & NA & NA & Plaque $^{*}$ & OR 1.17(1.04-1.32) \\
\hline Pulse pressure & Lovett, 2003 & Cohort study & NA & 3,018 & $62 \pm 8$ years & 27.77 & 12 months & 346 & Plaque $^{*}$ & OR 2.07(1.25-3.44) \\
\hline Total cholesterol (per $1 \mathrm{mmol} / \mathrm{L}$ ) & Sato, 2013 & Cross-sectional & 2005-2012 & 236 & $56 \pm 13(19-86)$ years & 34.30 & NA & NA & Plaque $^{*}$ & OR $0.93(0.72-1.20)$ \\
\hline Hypercholesterolemia & Huang, 2012 & Cohort study & 1981-1982 & 1,626 & $47.8 \pm 8.1$ years & 64.52 & 9 years & 431 & CIMT & $P<0.001$ \\
\hline Total cholesterol (per 1-SD) & Gardener, 2009 & Cross-sectional & 1993-2001 & 1,804 & $68.5 \pm 10.1$ years & 60.20 & NA & NA & Plaque $^{*}$ & OR $1.12(1.01-1.25)$ \\
\hline \multicolumn{11}{|l|}{ Hypertriglyceridemia } \\
\hline Triglyceride (per $1 \mathrm{mmo} / \mathrm{L}$ ) & Sato, 2013 & Cross-sectional & 2005-2012 & 236 & $56 \pm 13(19-86)$ years & 34.30 & NA & NA & Plaque $^{*}$ & OR $1.15(0.85-1.59)$ \\
\hline Hypertriglyceridemia & Huang, 2012 & Cohort study & 1981-1982 & 1,626 & $47.8 \pm 8.1$ years & 64.52 & 9 years & 431 & СIMT & $P<0.001$ \\
\hline Triglyceride (per 1-SD) & Gardener, 2009 & Cross-sectional & 1993-2001 & 1,804 & $68.5 \pm 10.1$ years & 60.20 & NA & NA & Plaque $^{*}$ & OR $0.99(0.88-1.10)$ \\
\hline Higher low-density lipoprotein & Huang, 2012 & Cohort study & 1981-1982 & 1,626 & $47.8 \pm 8.1$ years & 64.52 & 9 years & 431 & CIMT & $P<0.001$ \\
\hline Low density lipoprotein (per $100 \mathrm{nmol} / \mathrm{L}$ ) & Johnson, 2010 & Cross-sectional & 2005-2007 & 1,504 & $45.0(37.8-53.0)$ years & 58.00 & NA & NA & Plaque $^{*}$ & OR $1.11(1.08-1.13)$ \\
\hline Low density lipoprotein (per 1-SD) & Gardener, 2009 & Cross-sectional & 1993-2001 & 1,804 & $68.5 \pm 10.1$ years & 60.20 & NA & NA & Plaque $^{*}$ & OR $1.14(1.02-1.27)$ \\
\hline \multicolumn{11}{|l|}{ Hyperuricemia } \\
\hline Uric acid & Oikonen, 2012 & Cross-sectional & 1980 & 1,985 & $30-45$ years & 53.50 & NA & NA & Plaque $^{*}$ & OR $1.00(0.99-1.01)$ \\
\hline Uric acid (per $1 \mathrm{mg} / \mathrm{dl})$ & Zhang, 2012 & Cross-sectional & 2008-2010 & 3,010 & 50 years & 0.00 & NA & NA & CIMT† & OR $1.24(1.04-1.47)$ \\
\hline \multicolumn{11}{|l|}{ Hyperhomocysteinemia } \\
\hline Hyperuricemia & Kawamoto, 2005 & Cross-sectional & 1996-2004 & 919 & $>60$ years & 56.69 & NA & NA & CIMT & OR $1.66(1.16-1.39)$ \\
\hline $\begin{array}{l}\text { Homocysteine (per unit increase log } \\
\text { homocysteine) }\end{array}$ & Nakhai-Pour, 2007 & Cross-sectional & NA & 376 & $60 \pm 11$ years & 0.00 & NA & NA & CIMT & $P<0.01$ \\
\hline Current smoking & Kianoush, 2017 & Cross-sectional & 2012 & 14,103 & $51.7 \pm 8.9$ years & 54.00 & NA & NA & CIMT & $P<0.001$ \\
\hline \multicolumn{11}{|l|}{ Obstructive sleep apnea syndrome } \\
\hline Obstructive sleep apnea syndrome & Fox, 2014 & Cross-sectional & 2006-2007 & 51 & $>40$ years & 41.18 & NA & NA & CIMT & $P=0.03$ \\
\hline Obstructive sleep apnea syndrome & Gunnarsson, 2014 & Cohort study & 1989 & 2,884 & $47.6 \pm 7.7$ years & 45.00 & 13 years & 2094 & Plaque $^{*}$ & OR $1.55(1.02-2.35)$ \\
\hline Habitual snoring & Kim, 2014 & Cohort study & 2005-2006 & 3,487 & $>40$ years & 48.10 & 4 years & 358 & CIMT† & $\begin{array}{l}\text { OR 1.11 (0.72-1.70) (man), } \\
1.80(1.13-2.87) \text { (woman) }\end{array}$ \\
\hline Heavy snoring & Lee, 2008 & Cohort study & NA & 110 & $45-80$ years & 46.36 & NA & 13 & Plaque $^{*}$ & OR $10.5(2.10-51.8)$ \\
\hline $\begin{array}{l}\text { Mean nocturnal } \mathrm{SaO}_{2}<92 \% \text { and } \\
\text { minimal nocturnal } \mathrm{SaO}_{2}<80 \%\end{array}$ & Baguet, 2005 & Cross-sectional & 2001-2004 & 83 & $48 \pm 11$ years & 10.84 & NA & $\mathrm{Na}$ & Plaque $^{*}$ & OR $3.10(1.00-9.40)$ \\
\hline \multicolumn{11}{|l|}{ Negative emotion } \\
\hline Depressive symptoms & Haas, 2005 & Cohort study & 1985-1988 & 219 & $30-60$ years & 9.70 & 10 years & 89 & Plaque $^{*}$ & OR $2.31(1.19-4.50)$ \\
\hline Depressive symptoms & Rice, 2009 & Cohort study & 1980 & 556 & $20-93$ years & 54.50 & 3.9 years & 0 & CIMT & $P=0.34$ \\
\hline Depression & Tiemeier, 2004 & Cross-sectional & 1997-1999 & 4,019 & $>60$ years & 57.77 & NA & NA & CIMT & OR $1.24(1.02-1.51)$ \\
\hline Job strain & Hintsanen, 2005 & Cross-sectional & 1980 & 1,020 & 32.3 years & 53.14 & NA & NA & CIMT & $\mathrm{P}=0.029$ (man), $\mathrm{P}>0.05$ (woman) \\
\hline Childhood sexual abuse & Thurston, 2014 & Cohort study & 1996-1997 & 1,402 & $59.55 \pm 2.7$ years & 100.00 & 12 years & 0 & CIMT & $P<0.05$ \\
\hline Air pollution & & & & & & & & & & \\
\hline $\begin{array}{l}\text { Traffic-related pollution (living less than } \\
150 \mathrm{~m} \text { (versus more than } 300 \mathrm{~m} \text { ) from } \\
\text { major roadways) }\end{array}$ & Wang, 2016 & Cohort study & 2000-2004 & 5,301 & $55.5 \pm 12.7$ years & 63.70 & 5 years & 501 & CIMT & $P=0.12$ \\
\hline Chronic exposure to biomass fuel & Painschab, 2013 & Cross-sectional & 2011 & 266 & $>35$ years & 54.00 & NA & NA & Plaque $^{*}$ & OR $2.60(1.10-6.00)$ \\
\hline Lifestyle & & & & & & & & & & \\
\hline Vegetable intake (each $10 \mathrm{~g} / \mathrm{d})$ & Blekkenhorst, 2018 & Cross-sectional & 1998 & 968 & $75.0 \pm 2.6$ years & 100.00 & NA & NA & CIMT & $P<0.01$ \\
\hline Vegetable nitrate intake (each $29 \mathrm{mg} / \mathrm{d})$ & Bondonno, 2018 & Cross-sectional & 2001 & 1,226 & $72 \pm 3$ years & 100.00 & NA & NA & СIMT & $P=0.04$ \\
\hline Fish intake ( $\geq 3$ times/week) & Johnsen, 2018 & Cross-sectional & 2001 & 3,900 & $45-74$ years & 49.03 & NA & NA & Plaque $^{*}$ & OR $1.32(1.01-1.73)$ \\
\hline $\begin{array}{l}\text { Exercise } 40-80 \text { min in length } 5 \text { days } \\
\text { per week }\end{array}$ & Park, 2017 & Cohort study & NA & 44 & $71.1 \pm 4.6$ years & 100.00 & 24 weeks & 3 & СIMT & $P<0.05$ \\
\hline $\begin{array}{l}\text { Egg consumption (per additional } \\
\text { egg/week) }\end{array}$ & Goldberg, 2014 & Cohort study & NA & 1,429 & $65.8 \pm 8.8$ years & 60.00 & 11 years & 0 & Plaque $^{*}$ & OR $0.89(0.80-0.98)$ \\
\hline Mediterranean diet vs. unhealthy diet & Buscemi, 2013 & Cross-sectional & 2011 & 929 & $10-54$ years & 65.00 & NA & NA & Plaque $^{*}$ & OR $1.34(0.72-2.52)$ \\
\hline Longer sleep duration ( $1 \mathrm{~h} / \mathrm{d})$ & Sands, 2012 & Cross-sectional & 1985 & 617 & $37-52$ years & 58.00 & NA & NA & CIMT & $\mathrm{P}=0.02$ (man), $\mathrm{P}=0.91$ (woman) \\
\hline Nutrient's density & Kesse-Guyot, 2010 & Cohort study & 1994-1995 & 1,026 & $35-60$ years & 48.44 & 7.5 years & 126 & CIMT & $P=0.40$ \\
\hline Vigorous activity & Kozakova, 2010 & Cross-sectional & 2001 & 614 & $44 \pm 8$ years & 60.26 & NA & NA & CIMT & $P<0.05$ \\
\hline Consume alcohol $>40 \mathrm{~g} / \mathrm{d}$ & Lee, 2009 & Cross-sectional & 2007-2008 & 4,302 & $>50$ years & 63.34 & NA & NA & Plaque $^{\star}$ & OR 1.81 (1.13-2.91) \\
\hline Drinking tea $\geq 3$ cups/d vs. none & Debette, 2008 & Cross-sectional & 1999-2001 & 6,597 & $>65$ years & 60.93 & NA & NA & Plaque $^{*}$ & $\begin{array}{l}\text { OR } 1.02 \text { (0.31-5.90) (man), } \\
0.47(0.20-1.11) \text { (woman) }\end{array}$ \\
\hline Continuous positive airway pressure & Hui, 2012 & Cohort study & 2005 & 50 & $49.5 \pm 1.4$ years & 18.00 & 12 months & 26 & CIMT & $P=0.002$ \\
\hline Vitamin supplementary & & & & & & & & & & \\
\hline Niacin $(1,000 \mathrm{mg} /$ day $)$ & Thoenes, 2007 & Cohort study & 2004-2005 & 55 & $>18$ years & 44.44 & 52 weeks & 10 & CIMT & $P=0.006$ \\
\hline Low-dose of antioxidant vitamins & Zureik, 2004 & Cohort study & 1994 & 1,302 & $52.6 \pm 4.7$ years & 49.80 & $7.2 \pm 0.3$ years & 140 & CIMT & $P=0.38$ \\
\hline Antihypertensive drugs & & & & & & & & & & \\
\hline Valsartan vs. placebo & Ramadan, 2016 & Cohort study & 2005-2008 & 120 & $21-80$ years & 49.17 & 2 years & 44 & Delta CMT & $\mathrm{P}=0.009$ \\
\hline $\begin{array}{l}\text { Metoprolol controlled release/extended } \\
\text { release vs. placebo }\end{array}$ & Wikstrand, 2003 & Cohort study & NA & 793 & $49-70$ years & NA & 3 years & 0 & Delta CMT & $\mathrm{P}<0.05$ \\
\hline Lipid-lowering drugs & & & & & & & & & & \\
\hline Enalapril at $10 \mathrm{mg} / \mathrm{d}$ vs. control & Hosomi, 2001 & Cohort study & 1997 & 98 & $\begin{array}{l}56.3 \pm 8.5 \text { years (control), } \\
56.4 \pm 8.7 \text { years (intervention) }\end{array}$ & 37.76 & 2 years & 7 & $\begin{array}{l}\text { Annual change of } \\
\text { CIMT }\end{array}$ & $P=0.011$ \\
\hline Pactimibe at $100 \mathrm{mg} / \mathrm{d}$ vs. placebo & Meuwese, 2009 & Cohort study & 2004-2005 & 881 & $\begin{array}{l}54.7 \pm 8.5 \text { years (control), } \\
55.5 \pm 8.5 \text { years (intervention) }\end{array}$ & 39.05 & 24 months & 165 & CIMT & $P=0.04$ \\
\hline Rosuvastatin at $40 \mathrm{mg} / \mathrm{d} v \mathrm{vs}$. placebo & Bots, 2009 & Cohort study & NA & 984 & $\begin{array}{l}57.0 \pm 6.0 \text { years (control), } \\
57.0 \pm 6.2 \text { years (intervention) }\end{array}$ & 40.65 & 24 months & 0 & $\begin{array}{l}\text { Annual change of } \\
\text { CIMT }\end{array}$ & $P<0.001$ \\
\hline $\begin{array}{l}\text { Simvastatin or atorvastatin vs. no } \\
\text { statin therapy }\end{array}$ & Yamagami, 2008 & Cohort study & 2001-2003 & 81 & $\begin{array}{l}65.4 \pm 6.9 \text { years (control), } \\
63.4 \pm 8.3 \text { years (intervention) }\end{array}$ & 42.00 & 1 year & 0 & Plaque thickness & $\mathrm{P}=0.008$ \\
\hline Glucose-lowering drugs & & & & & & & & & & \\
\hline Pioglitazone vs. placebo & Christoph, 2015 & Cohort study & 2007-2010 & 54 & $\begin{array}{c}62.2 \pm 10.0 \text { years (control), } \\
59.5 \pm 10.4 \text { years (intervention) }\end{array}$ & 18.52 & 9 months & 0 & CMT & $P>0.05$ \\
\hline
\end{tabular}

